\title{
Barriers and Chemistry in a Bottle: Mechanisms in Today's Oxygen Barriers for Tomorrow's Materials
}

\author{
Youri Michiels ${ }^{1, *}$ (D), Peter Van Puyvelde ${ }^{2}$ and Bert Sels ${ }^{1, *}$ \\ 1 Centre for Surface Chemistry and Catalysis, KU Leuven, 3001 Heverlee, Belgium \\ 2 Soft Matter, Rheology and Technology, KU Leuven, 3001 Heverlee, Belgium; \\ peter.vanpuyvelde@kuleuven.be \\ * Correspondence: youri.michiels@kuleuven.be (Y.M.); bert.sels@kuleuven.be (B.S.); \\ Tel.: +32-16-377690 (Y.M.); +32-16-321593 (B.S.)
}

Received: 3 June 2017; Accepted: 21 June 2017; Published: 28 June 2017

\begin{abstract}
The stability of many organic compounds is challenged by oxidation reactions with molecular oxygen from the air in accordance with thermodynamics. Whereas glass or metal containers may protect such products, these packaging types also offer severe disadvantages over plastics. Large-scale packaging, especially for food and beverage industries, has shifted towards polymeric materials with passive and active oxygen barrier technologies over the last decades. Even though patent literature is flooded with innovative barrier systems, the mechanisms behind them are rarely reported. In a world where packaging requirements regarding recyclability and safety are continuously getting stricter, accompanied by the appearance of emerging applications for plastic oxygen barriers (such as organic semi-conductors), research towards new materials seems inevitable. To this cause, proper in-depth knowledge of the existing solutions is a prerequisite. This review therefore attempts to go deep into the problems at hand and explain the chemistry behind the existing solution strategies and finally discusses perspectives suggesting new applications such as organic light-emitting diodes (OLEDs) and solar cells.
\end{abstract}

Keywords: oxygen barrier; oxygen scavenger; packaging; poly(ethylene terephthalate); organic electronics

\section{Introduction}

In recent years, the world of packaging has been shifting continuously towards the application of more plastic-based materials as replacements for, e.g., aluminum and glass. These traditional materials have a high production cost and high carbon footprint compared to polymeric containers [1-3]. Additionally, plastics are less fragile and extremely lightweight. However, while glass and aluminum are highly impermeable to gases, small molecules may still be able to move in between polymer chains. Therefore, the plastics industry is forced to develop new technologies to meet the packaging requirements of certain products, such as juices, beers and wines. As such, specific barrier solutions are employed in order for these products to retain an appropriate lifetime. Depending on the contents of the packaging, demands can be imposed for retaining light, water, $\mathrm{CO}_{2}$ and /or $\mathrm{O}_{2}$, etc. These demands are quantified in a single parameter, namely the shelf life. The shelf life is defined as the period of time ranging from the packaging of a product to the moment wherein the product is no longer of acceptable quality to be sold. A wide range of solutions has been brought onto the market in order to provide the product's specific shelf life demands. These can be subcategorized into active and passive barriers, depending on the type of molecular interactions (i.e., chemical reactions, adsorption, desorption, etc.) that occur between the barrier compound and the targeted molecule $[4,5]$.

For many applications, the exclusion of oxygen from the package is critical. The oxidative nature of this molecule can quickly deteriorate the quality of a packaged product [6,7]. Depending on 
this product, the requirements for the oxygen barrier to achieve a sufficient shelf life may vary. Fruit preservation thrives best under oxygen levels of $2-5 \%$, imposing the need for very slow scavengers and the creation of a steady state between permeation and oxygen removal $[8,9]$. In meats and in many beverages (ex. juice, beer, wine, etc.) any oxygen could be harmful. Packagers should therefore aim for the exclusion of as much oxygen as possible until other contaminations will limit the shelf life. For example, in solid products such as meats, microbial threats limit the shelf life to 8-9 weeks anyway, so oxygen barriers that provide protection for at least this long are sufficient [10]. Aseptic filling of liquid products provides a much better protection from microbial contaminants, so a longer potential shelf life can be achieved in comparison to the modified atmospheric packaging (MAP) of solid foods. Therefore, the most potent oxygen barriers in the state-of-the-art are preferred for beverages to achieve maximum durability [11]. Aside from foodstuffs, other technical applications for polymeric oxygen barriers can comprise the protection of organic electronics (e.g., organic light-emitting diodes (OLEDs) and solar cells) [12-14]. OLED-structures comprise molecules with high conjugation that may excite and subsequently luminesce when an electric current is applied. At these excited energy levels, it may readily interact with water, but also oxygen, as will be further explained below. The substrate on which the electrodes and the organic semi-conductor phase of OLEDs are grown should therefore provide long-lasting protection from oxygen and water. The encapsulations in the traditional set-up are glass plates and metal lids, which achieve excellent performances. Now the industry is focusing on producing its next generation, flexible OLEDs. The targeted flexibility can only be achieved with the exclusion of the rigid glass plates. Transparent polymers with high barrier properties would offer an appropriate alternative, but the current solutions are still expensive and insufficient for long lifetimes. Applications encompass, amongst others, the incorporation of flexible computer screens in clothing. A scheme listing the relative oxygen barrier desires for above applications is given in Figure 1.

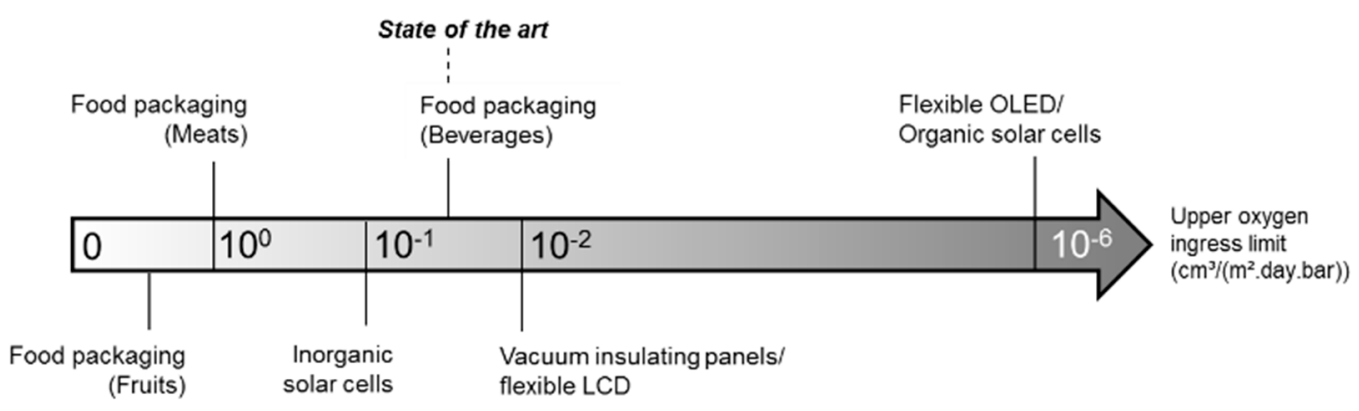

Figure 1. Approximate values for the permeation limitations that oxygen barriers should provide in different applications. The values are expressed as the maximum volume of oxygen that may enter $1 \mathrm{~m}^{2}$ of barrier surface area each day at 1 bar of external oxygen pressure, averaged over the relevant lifetime $[8,10,14]$.

Many inventions in the field of oxygen-resistant packaging materials have been investigated in confidential industrial environments, while little fundamental research is published on the science behind the oxygen barrier. This is especially true for the active barrier chemistry, which is also more complicated. This publication attempts to reach beyond the commercial discussion and will provide a scientific background to existing solutions to encourage a more focused research for new packaging compositions and the incorporation of packaging technologies in other applications such as OLEDs. This paper operates from the perspective of the PET-bottle industry due to the variety of available technologies and the high barrier and transparency requirements. Moreover, there is still a great need for improvements within this application. The technologies discussed here can also be further extrapolated towards other structural polymers and flexible films. Consequentially, the protection layers of organic electronics will henceforth also be incorporated in the general term of "packaging". 


\section{Background}

\subsection{Oxidative Degradation Mechanisms}

In order to increase the shelf life by eliminating microbial contaminants, bottled products with high contamination risks undergo either aseptic filling, hot filling or pasteurization [11,15,16]. The recent breakthroughs in producing thermally resistant jars have opened up more possibilities for PET to compete with glass in the hot-filled food area. The new technologies have increased the thermal stability and new designs have reduced the containers deformation during the filling process $[17,18]$. Low-acidity products such as sauces, pickled vegetables and fruit preparations are prone to microbial contamination without a high temperature decontamination step. These hot-filled products have now been made available for packaging in PET. However, removing microbial threats by either thermal or chemical treatments does not exclude the occurrence of chemical reactions with food constituents that might occur during the shelf life of the product. The oxidation sensitivity of specific food components leads to a high necessity for oxygen removal. To indicate the importance of preserving foodstuffs under anaerobic conditions, a summary has been made of the major oxidative degradations for some common food and beverage components.

\subsubsection{Chemistry of Oxygen}

Thermodynamically, molecular oxygen is a highly oxidative species, as evidenced by highly exothermic reactions such as burning. However, the reaction of oxygen with organic compounds is hindered kinetically. Initiation of an oxidative reaction with molecular oxygen requires the crossing of a large energy barrier. Oxygen molecules can be excited to a singlet state with the absorption of $95 \mathrm{~kJ} \mathrm{~mol}^{-1}$ of energy. This might be attained from heat during burning processes, but at room temperature the major pathway of oxygen activation in food and beverages is the excitation of photosensitizers [19]. Visible and UV-light provide photon energies above $150 \mathrm{~kJ} \mathrm{~mol}^{-1}$ and can therefore act as a source to cross the kinetic barrier. In order for this energy to get transferred to oxygen, the light first needs to be absorbed by a chromophore, which can be provided by organic molecules called photosensitizers. Such compounds encompass dyes and pigments (e.g., methylene blue, chlorophyll, etc.), riboflavin or sometimes other aromatic hydrocarbons [20]. Active compounds in OLEDs and organic solar cells get similarly excited before emitting visible light or after absorbing visible light, providing the same energy levels. They therefore possess a photosensitizing ability as well and are present in a much more concentrated form, proving their high need for protection from oxygen [21-24].

Oxygen in its most abundant form is a diradical with a quantum spin number of 3 , noted as a triplet. This is the most stable form, following Hund's rule [25]. It is visualized in Figure 2. Triplet oxygen prefers to react through one-electron oxidations. However, this is unfavorable for most organic molecules that are usually in a fully paired state with quantum spin number 1 (singlet state). An exception to this rule is the presence of organic radical species, providing unpaired electrons that triplet oxygen is able to readily attack [19].

Photosensitizing compounds absorb light in order to form an excited singlet state. In other words, an electron in the $\pi$-orbital, also noted as the highest occupied molecular orbital (HOMO) will jump to the anti-bonding $\pi^{*}$-orbital, which is the lowest unoccupied molecular orbital (LUMO). This excited electron will fall back to a lower energy state. This can be either to the ground state, emitting heat or light (fluorescence) or it can be subjected to intersystem crossing. In the latter case, the now separated $\pi$-electron pair will align its spin, thus creating a triplet state. Figure 3 shows these conversions in the molecular orbitals of a photosensitizer [19].

When at any time intersystem crossing does occur, the excited triplet state sensitizer can again return to the ground state by emitting heat or light (phosphorescence) or it can activate triplet oxygen via two reaction types, depending on the sensitizer and the substrate (Figure 4) [26]. Type I reactions require molecules with an easily abstractable electron or hydrogen atom. It is therefore most common for substrates with a phenolic structure and quinones. Type I reactions are driven by a radicalar 
mechanism. Alternatively, the sensitizer may donate its own electrons to triplet oxygen in the formation of a superoxide radical. Type II photosensitization occurs by converting the triplet oxygen molecules to singlet oxygen. Singlet oxygen then readily reacts with double bonds in a non-radicalar mechanism $[19,26]$. Each sensitization type ultimately leads to the formation of peroxides, which can further propagate radically.

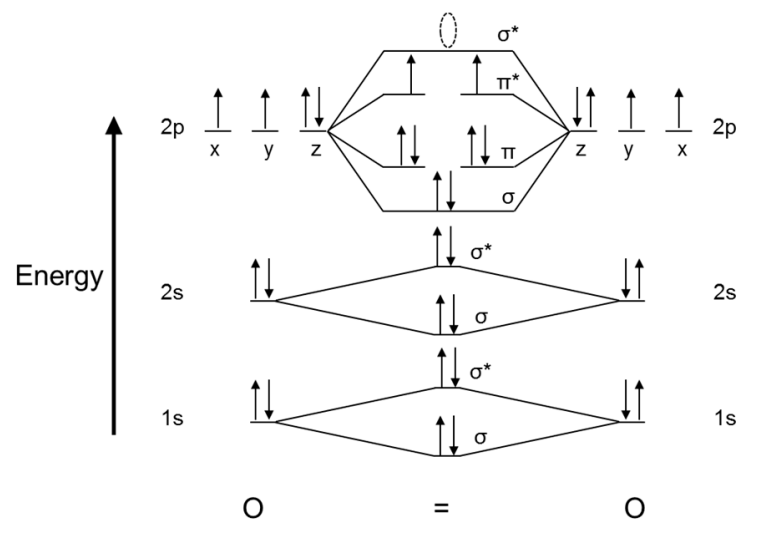

Figure 2. Molecular orbitals of triplet oxygen [19].

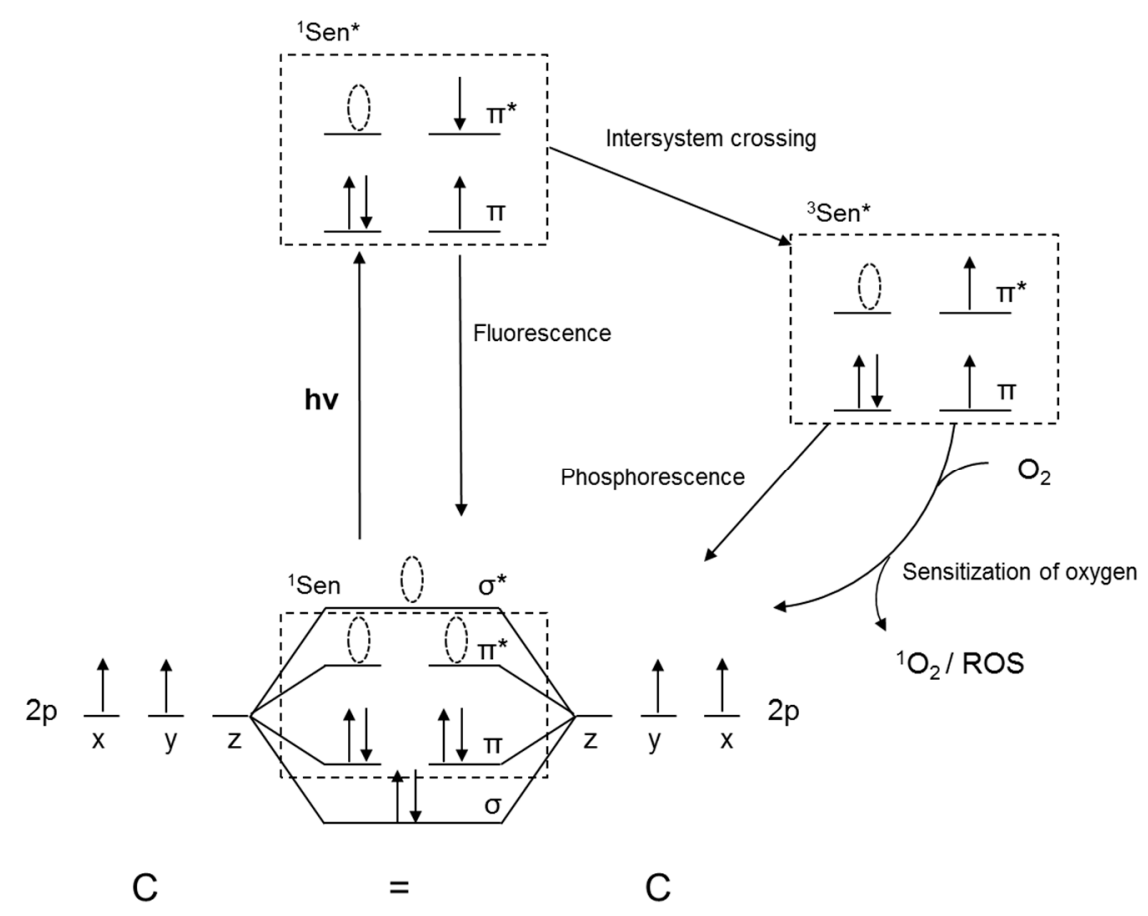

Figure 3. Electronic conversions in the highest occupied molecular orbital (HOMO) $(\pi)$ and lowest occupied molecular orbital (LUMO) $\left(\pi^{*}\right)$ of an unsaturated carbon-carbon bond after light absorption. Molecular orbitals of the $1 \mathrm{~s}$ and $2 \mathrm{~s}$ atomic orbitals are left out of the figure.

Beers and wines, especially red wines, contain many pigments and highly oxidizable compounds. Protection from light is required here to limit the oxidation processes. Usually, the packaging is adapted to this by adding green or amber colorants to the bottles. The green bottles will block UV-light, limiting photosensitization in this area, while amber colorants also block a wider range of the visible light [27]. The sensitizing effect is also very intense in milk, where vitamins $A$ and $B_{2}$ are very prone to oxidation [28-30]. Dairy products are therefore usually packaged in a completely opaque packaging, but often without any extra oxygen barrier added. 


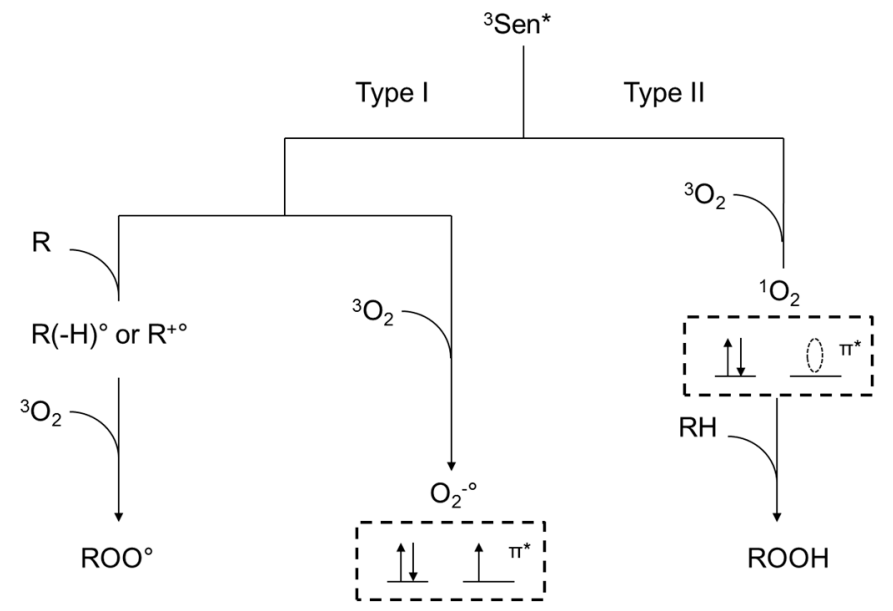

Figure 4. Sensitization of triplet oxygen to reactive oxygen species. The initiating component is the excited triplet state of a sensitizer (e.g., dyes or pigments) after light absorption and subsequent intersystem crossing. The electronic configurations of the anti-bonding $\pi$-orbital for two excited oxygen states, superoxide $\left(\mathrm{O}_{2}{ }^{-\circ}\right)$ and singlet oxygen $\left({ }^{1} \mathrm{O}_{2}\right)$ are given in the dotted boxes [19].

In organic solar cells, a photosensitizer is present as the so-called p-type semi-conductor phase, which is also able to undergo intersystem crossing and subsequent oxygen activation. Additionally, this phase is in contact with an electron acceptor (also noted as the n-type semi-conductor phase) with a LUMO that has a lower energy than the p-type semi-conductor. The electron-donating p-type can consist of a wide variety of molecular structures (thiophene-based, carbazole-based, etc.), but the electron accepting n-type rather consistently contains fullerenes [23].

The mechanism of the solar cell relies on the absorption of light by the photosensitizing p-type semi-conductor. At the interface between the two semi-conductor phases, the excited electron can be donated to the fullerene structure, creating two radical species. As both the positively charged donor and the negatively charged acceptor are connected to electrodes by semi-conductive polymer chains, an electric potential is created and the radicalar charges move to their respective electrode. Both of these radicalar species are prone to the activation of triplet oxygen, similar to type I photosensitization. In OLED structures, this approach is similar but reversed to produce light from electricity [23,24].

Following the initiation, the propagation step will further break down the relatively unstable organic peroxyl groups to reactive oxygen species (ROS), which is a collective term for oxygen radicals such as peroxyl-, superoxide- or hydroxyl-radicals [31]. The decay of peroxyl groups may involve many different pathways, leading to different products such as carbonyl groups, alcohols, unsaturated carbon bonds or epoxides. An exemplary pathway is the reaction of two peroxyl radicals through a short-lived tetroxide intermediate, given in Figure 5 [32]. The differentiation of the reaction products shows the complexity of the possible reactions in an oxidative environment. The first reaction is a radical termination reaction, but the others will propagate the radical chain. As such, the oxidation reactions are autocatalytic and therefore referred to as the autoxidation of organic compounds.

The effect is increased in the presence of middle to late transition metal ions $(\mathrm{Fe}, \mathrm{Cu}, \mathrm{Mn}, \mathrm{Co}$, etc.). These metals can be converted from one stable oxidation state to another with the exchange of one electron. They are therefore very susceptible to radical species in reactions called the Fenton-like reactions. The name is a reference to Henry J. Fenton who was the first to report the activation of hydrogen peroxide by iron in 1894 [33]. Fenton chemistry involves the activation of relatively stable peroxides by transition metals to highly reactive radicals, thereby catalyzing radical oxidation in aqueous environments. These reactions are utilized in applications such as water treatment or paint drying, but are mostly known for their negative impact as it promotes degradation of food and induces oxidative stress in cell structures [34-37]. The reactivity of a Fenton-catalyst includes a list of many different one-electron exchanges between the metal ions, ROS and organic substrates. The Haber-Weiss 
cycle, consisting of reaction (1) and (2), shows the two most critical reactions in Fenton chemistry, including the original Fenton reaction [38-40].

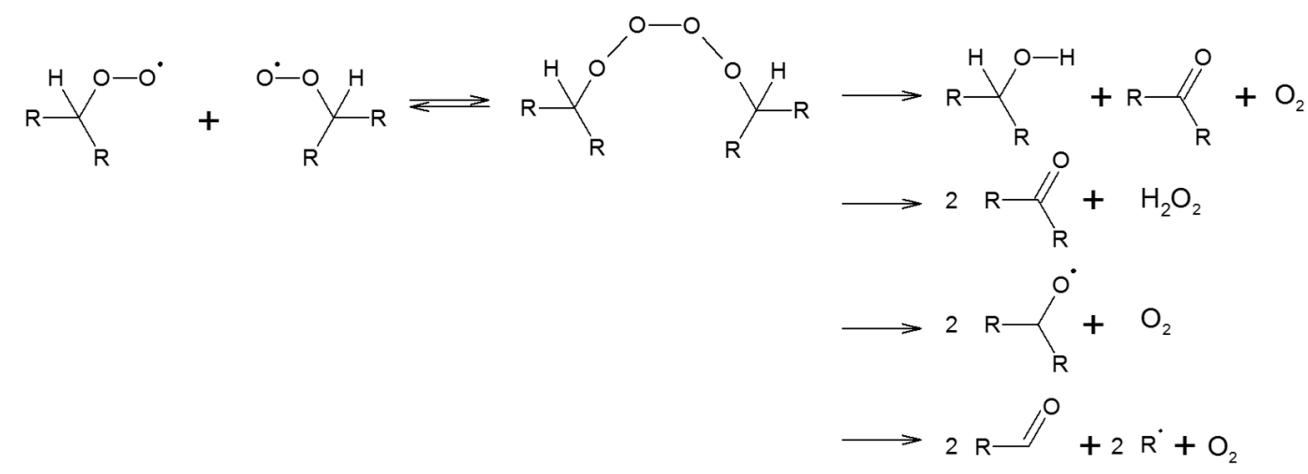

Figure 5. Bimolecular decay of organic peroxyl radicals. After a tetroxide transition state, different products may be formed, either (a) terminating the radical chain or (b) propagating it [32].

The initial peroxide molecules can be either organic or $\mathrm{H}_{2} \mathrm{O}_{2}$, as shown here. Organic peroxides can be created by the mechanisms described above or they can be added in applications such as water treatment.

$$
\begin{gathered}
\mathrm{H}_{2} \mathrm{O}_{2}+\mathrm{Fe}^{(\mathrm{III})} \rightarrow \mathrm{Fe}^{(\mathrm{II})}+\mathrm{OOH}^{\circ}+\mathbf{H}^{+} \\
\mathrm{H}_{2} \mathrm{O}_{2}+\mathrm{Fe}^{(\mathrm{II})} \rightarrow \mathrm{Fe}^{(\mathrm{III})}+\mathrm{OH}^{\circ}+\mathrm{OH}^{-}(\text {Fenton reaction })^{\circ}
\end{gathered}
$$

\subsubsection{Oxidation of Unsaturated Compounds}

In food and beverages, there are several components that are prone to oxidation as the organic substrate in the previous section. They can be differentiated according to the photosensitization type.

Unsaturated compounds in packaged food products are usually the first to become oxidized. Unsaturated fatty acids are the most typical examples, but also terpenes and vitamin A possess the same sensitivity issues [41].

Due to the presence of pigments and dyes in foodstuffs, activation of molecular oxygen can occur as described earlier and the resulting singlet oxygen (type II photosensitization) will oxidize unsaturated bonds at room temperature. Type I photosensitization may also occur with unsaturated molecules, but only significantly for those that are susceptible to $\mathrm{H}$-abstraction. Polyunsaturated fatty acids such as linoleic acid (C18:2) and linolenic acid (C18:3) provide a weak C-H bond in between the double bonds, as indicated in Figure 6. Even though the singlet oxygen initiation still maintains a higher reaction rate in the order of magnitude 4 , the radical initiation is sensitively increased by this $[39,42,43]$.

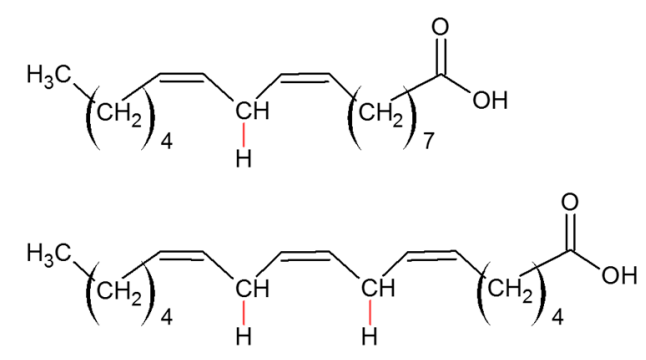

Figure 6. Molecular structures of (a) linoleic acid and (b) linolenic acid, highlighting the hydrogen atoms that are the most sensitive to $\mathrm{H}$-abstraction due to conjugative stabilization after radical formation. 
Oleic, linoleic and linolenic acid are present in beer after the malting of barley, where they are released by malt lipases from oils containing the esterified fatty acids. The breakdown of these components has been widely related to a cardboard taste after beer staling. The fatty acids are oxidized to form new carbonyl structures of which trans-2-nonenal is the most prominent [44].

In organic electronics, the semi-conductive polymer chains and chromophores are highly conjugated unsaturated structures. They are also predominantly degraded by singlet oxygen in a type II photosensitization. In Section 2.1.1, it was noted that a type I-like photosensitization is also possible after charge separation. Both mechanisms are therefore relevant, but initiation involving a singlet oxygen will consistently occur at a higher rate $[45,46]$.

\subsubsection{Oxidation of Alcoholic Compounds}

Most alcoholic structures in food (ethanol, monophenols, etc.) are initiated by a type I photosensitization. This initiation type includes the breaking of covalent bonds to radical compounds and transpire much slower than the non-radicalar type II reactions. Alcohols are therefore less susceptible to initiation as unsaturated fatty acids and will usually not degrade significantly at room temperature. However, they are very easily incorporated in a propagation chain initiated by lipids [47-49]. Most polyphenols and quinones provide more conjugation than other alcohols. The initiation of such molecules is facilitated by the stabilization of the resulting radicals. These compounds are mostly present in food as the reaction products of monophenol oxidation, so this is an additional form of autocatalysis in the oxidation mechanism, aside from the exponential propagation of radicals [47-49]. The resulting functional groups are again carbonyl functions, capable of performing Maillard reactions. Especially in wine, an important reaction is the aldol-condensation of acetaldehyde, created by ethanol oxidation, with anthocyanins or flavenol to form other colored products [48,50].

Fruit juices, the largest market for oxygen barrier packaging, owe their oxygen sensitivity mostly to their high vitamin content. Vitamins $\mathrm{C}$ and $\mathrm{E}$ are both phenolic compounds and are sometimes even employed as active oxygen scavengers in packaging. This will be discussed further in Section 4.1.

\subsection{Measuring Oxygen in Packaging}

In order to determine whether a package can provide sufficient protection from oxygen, several quality parameters have been defined [51-53].

- Oxygen transmission rate (OTR). The most common definition of OTR is the volume of $\mathrm{O}_{2}$ per package per day. The exact conditions need to be specified and preferably resemble the real storage environment of the packaging. Usually, the partial oxygen pressure is regulated to $0.21 \mathrm{~atm}$, but temperature may vary between $20{ }^{\circ} \mathrm{C}$ and $25^{\circ} \mathrm{C}$ and humidity between $0 \%$ and $100 \% \mathrm{RH}$ [54,55].

- Permeability. This is usually defined in terms of Equation (3) [52].

$$
\mathbf{P}=\frac{\mathbf{V} \mathbf{L}}{\operatorname{At} \Delta \mathbf{p}}
$$

With $\mathrm{P}$ the permeability (most commonly expressed in units of $\mathrm{cm}^{3} \mathrm{~mm} \mathrm{~m}^{-2} \mathrm{day}^{-1} \mathrm{~atm}^{-1}$ ). Herein, $\mathrm{V}$ is the volume of the gas permeating in time $\mathrm{t}\left(\mathrm{cm}^{3}\right.$ day $\left.{ }^{-1}\right), \mathrm{L}$ is the thickness of the film or bottle wall (mm), A the surface area of the film over which permeation is measured $\left(\mathrm{m}^{2}\right)$ and $\Delta \mathrm{p}$ the difference in partial pressure of the gas inside and outside the packaging (atm). The effect of temperature can then be quantified by a conventional Arrhenius equation, as shown in Equation (4) [52].

$$
\mathbf{P}=\mathbf{P}_{0} \mathbf{e}^{-\frac{E_{P}}{R T}}
$$


With $\mathrm{P}$ the permeability at temperature $\mathrm{T}(\mathrm{K}), \mathrm{P}_{0}$ a pre-exponential factor $\left(\mathrm{cm}^{3} \mathrm{~mm} \mathrm{~m}^{-2}\right.$ day $^{-1}$ $\left.\mathrm{atm}^{-1}\right), \mathrm{E}_{\mathrm{p}}$ the activation energy for the permeability action $\left(\mathrm{J} \mathrm{mol}^{-1}\right)$ and $\mathrm{R}$ the ideal gas constant $\left(\mathrm{J} \mathrm{mol}^{-1} \mathrm{~K}^{-1}\right)$. The activation energy of oxygen in amorphous PET has been determined to be $37.7 \times 10^{3} \mathrm{~J} \mathrm{~mol}^{-1}[52]$.

- Barrier improvement factor (BIF). This is a unitless factor, usually used in a commercial setting, defined as the ratio between either OTR or permeability of the given barrier composition and a standard packaging [53].

A common mistake is that OTR is often inputted as $V / t$ in Equation (3) to calculate permeability. However, whereas permeability is a measure for the material at a given humidity and crystallinity, OTR is very specific for the examined package design and is not a representation for the material used or the packing size ( $200 \mathrm{~mL}$ bottles versus $1 \mathrm{~L}$ bottles). After all, packaging, especially bottles, usually consists of several areas with different permeabilities (e.g., the thin, stretched body versus the thick, amorphous bottom of a bottle). The material distribution of a bottle may influence the ratio of crystalline to amorphous wall surface, thickness gradients and possibly the multilayer position [56]. OTR can therefore be different for two bottles of the same material but in different shapes.

As stated, humidity and crystallinity will also have an effect on oxygen permeation and this is often harder to control than wall distribution. These effects can be explained by separating permeability into a diffusive and solubility factor according to Equation (5).

$$
\mathbf{P}=\mathbf{D} \mathbf{S}
$$

While solubility $S\left(\mathrm{~cm}^{3} \mathrm{~cm}^{-3} \mathrm{~atm}^{-1}\right)$, expressed as the volume of permeant dissolved per volume of polymer $\left(\mathrm{cm}^{3} \mathrm{~cm}^{-3}\right)$ at a determined partial pressure (atm), is an indication to the free volume in the matrix, diffusivity (D) (in $\mathrm{m}^{2} \mathrm{~s}^{-1}$ ) is a measure of channel formation, enabling the gas molecule to move through this free volume [55].

Specified for oxygen through a PET-wall, studies have shown that high crystallinity reduces both factors since the free volume in crystallites is lower. This affects solubility, but also creates obstacles that will increase the diffusion path length. High humidity will increase diffusion due to swelling, but will also lower the free gaseous volume and thus decreasing solubility by a factor relating to the dissolution of oxygen in water. Overall, the research has shown that both a high crystallinity and a high humidity will increase the oxygen barrier properties of PET [56,57].

For active barriers, often none of the above parameters are sufficient qualifiers for barrier efficiency. Oxygen scavengers react with both oxygen from inside and outside the package. The reaction rate usually changes in time and when it exceeds the passive permeation of oxygen, residual oxygen in the package is also scavenged. Permeability measurements may then even appear negative. In this case, the barrier efficiency can only be visualized correctly by plotting the scavenging rate or the oxygen concentration in the package in function of time over the entire shelf life [58].

Several methods to measure or indicate oxygen concentration are available on the market. In the next paragraphs, the most common techniques will be discussed.

\subsubsection{Colorimetric Indicators}

The oxidation of a dye to create a differently colored substance is a relatively simple method. The dyes can be present as a gel or liquid with which the examined bottle is filled. More practical can be the solid versions that are glued to the inner wall of the packaging [59]. There are multiple variations on this type, but the most well-known kind employs a methylene blue dye in a solid matrix that starts from a reduced, colorless leuco-form and can be easily oxidized to a blue conjugated structure [60]. The presence of glucose in the indicator can reverse this reaction by reducing it back to its colorless state [60-62]. The reverse reaction is slow, so the incorporation of a $\mathrm{TiO}_{2}$-photocatalyst may cause the dye to reset only after a light-trigger. Controlling the reverse reaction is preferred to avoid interference with ongoing experiments [61]. Other light-sensitive systems with similar reaction kinetics comprise 
of riboflavin as a fluorescent dye and ethylene-diaminetetraacetic acid (EDTA) as photo-reducing agent [63].

The sacrificial reductants in each of these indicators are only present in a limited quantity, so the amount of measurements that can be executed are limited as well. However, it is possible to create fully reversible colorimetric oxygen indicators, based on hemoglobin as present in human blood [64]. The iron-functionalized proteins reversibly bind oxygen for transport in the bloodstream, thereby granting it its typical red color. However, such proteins are unstable in storage and degrade within days. As an alternative, a synthetic cobalt-complex has been found that can reversibly bind oxygen for several months [64]. These visual indicators are easy and cheap, but often difficult to quantify and exhibit only limited sensitivity [59,62]. They are therefore not employed very often as an analysis method, but can be used in intelligent packaging inks as an indicator for the consumer [65]. Recently, another method, called Tunable Diode Laser Absorption Spectroscopy (TDLAS) has been getting more attention as well $[66,67]$. A laser beam at narrow wavelengths around $760 \mathrm{~nm}$ and attenuated to a specific packaging may decrease in intensity throughout a package after light absorption by oxygen. Lambert-Beer's law can then provide a quantified oxygen concentration.

\subsubsection{Potentiometric Detectors}

Oxygen concentration can also be detected potentiometrically, leading to higher sensitivities than in traditional colorimetric methods. A gaseous flow with an unknown oxygen concentration contacts a platinum electrode on the inside of an electrolyte tube, usually alumina or yttria stabilized zirconia (YSZ) for high temperatures $[68,69]$. The oxygen acts as an electron acceptor and generates positively charged holes in the electrode, creating the potential for electron flows between the measuring electrode and the reference electrode on the other side of the electrolyte. The reference electrode is in contact with a known oxygen concentration (most often air) [68]. The electrical voltage can then be measured and is directly related to the oxygen concentration.

There are two main methodologies in practice to measure oxygen permeation employing these detectors. The first is a destructive method in which a package is punctured in order to achieve contact between the packaged atmosphere and the electrode. In the course of the shelf life, the real oxygen concentration of the packaging is measured several times. The disadvantages of such a destructive method is that every data point requires a different packaging sample and that the measurements span a large time period [70].

As a second method, the inside of a package is in contact with a gas flow of known composition, while it remains in contact with air on the outside. The outgoing gas stream is analyzed potentiometrically to indicate the rate of oxygen ingress [71-74]. Limitations here include not being able to simulate real life conditions, meaning no liquids can be present. This is especially disadvantageous for active barriers that are only active in contact with water.

\subsubsection{Fluorescence Detectors}

A technology based on fluorescence is employed an alternative to the previous techniques. It is non-destructive, highly sensitive and can be used in real conditions [75-77]. The method employs a small sticker to be glued on the inside of the package. It contains metallic complexes (mostly Ru or Pt) that will fluoresce when excited by certain wavelengths. Light is both emitted and subsequently absorbed again by a fluorescence-detector that can be placed on the outside of the package. The fluorescence of the complex is quenched as the excited energy of the complex is transferred to molecular oxygen in the formation of the singlet state. When in contact with an oxygen-rich environment, the fluorescence signal will therefore exhibit a long apparent fluorescence time and a low emission intensity. This can be related accurately even to low concentrations of oxygen present in the package [62].

Measuring oxygen through such a sensor inside the package can deliver the real conditions over an entire shelf life and produce very realistic results. However, as shelf lives of certain bottles 
can extend over several years, such samples require monitoring over the full period and storage in a controlled environment to dismiss seasonal changes. Additionally, colored bottles may often interfere with the measurements as it can absorb both the emitted or the fluoresced light. Potentiometric methods will always need to be performed for these bottles. Still, this is the best quantification method for clear active packaging solutions, being able to plot oxygen concentration of a certain bottle in time. The sensor dot can also be used in a flushed system comparable to the second potentiometric method to measure quickly the OTR of a package, but again no liquids are compatible with this method [78].

\section{Passive Barriers}

The previous sections describe the need for an oxygen-free environment. As polymeric packaging always allows for some oxygen permeation, this has prompted many researchers in the past to decrease oxygen permeability of commodity plastics by adding a barrier material. Usually, applying the pure barrier material as a packaging material is impossible due to insufficient mechanical properties and/or high cost. Passive barriers specifically attempt to physically slow down oxygen ingress in the packaging wall. In contrast, the goal of active oxygen barriers is chemically removing the oxygen and is very little related to permeability. This will be discussed in Section 4 . The passive barrier property of a material is best described by its permeability. Equation (3) from Section 2.2 is therefore revisited here.

This equation can be rewritten to provide for a formula that can model the total oxygen ingress in a packaging construct of a material with known permeability. Equation (6) captures the oxygen flux $Q$ $\left(\mathrm{cm}^{3}\right.$ day $\left.^{-1}\right)$ diffusing into the contents of the package.

$$
\mathrm{Q}_{\text {package }}=\int_{\mathrm{A}} \frac{\mathbf{P}}{\mathrm{L}} \boldsymbol{\sigma}\left(\mathrm{p}_{\mathrm{O}_{2, \text { outside }}}-\mathrm{p}_{\mathrm{O}_{2, \text { inside }}}\right) \mathrm{d} \boldsymbol{\sigma}
$$

with $\sigma$ representing an infinitesimally small portion of surface area of the package.

For films, most often the permeability is approximately equal across the entire surface. However, bottles for example own several zones in which the permeability can severely change. The cap, usually consisting of HDPE, allows for more oxygen to permeate than a PET-bottle wall [79,80]. Additionally, due to the blowing process, the bottom and neck of a PET-bottle are more amorphous and thicker than the body. Both $\mathrm{P}$ and $\mathrm{L}$ are therefore functions of bottle area, even for the same polymer material [80].

Passive barrier solutions are all attempting to decrease permeability across the PET-wall. Three different techniques have been developed to incorporate low permeability materials in plastics and thereby raising the passive barrier. A visual representation is given in Figure 7.
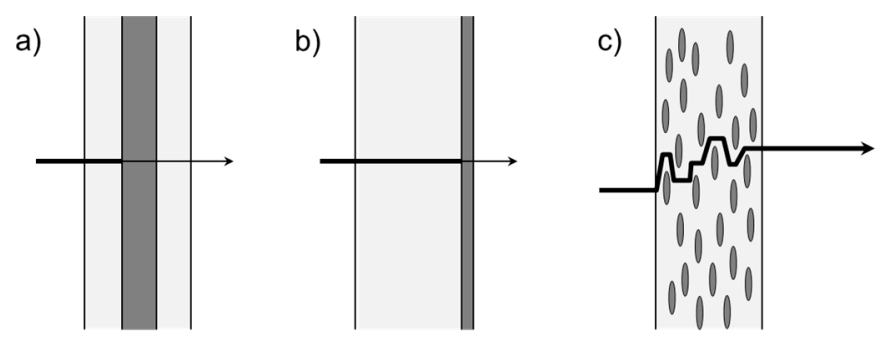

Figure 7. Three strategies to increase the barrier properties of a structural polymer (light color) by the addition of a low permeable material (dark color): Multilayer (a), coating (b) and composites (c). The solid arrow represents the oxygen flow from outside the packaging (left) to the inner content (right).

\subsection{Multilayer}

A multilayer barrier usually exists of 3 or more polymeric layers. The outer layers are structural layers, while the inner layer is a polymer that exhibits superior barrier properties. Films and bottles with this technology are prepared by co-extrusion, resp. co-injection, employing two extrusion barrels 
on one machine, specifically designed for these applications [81-83]. While oxygen permeability for a monolayer can be calculated through Equation (3), for multilayer barriers a summation, expressed by Equation (7) needs to be employed [52]. Permeabilities for several barrier materials are listed in Table 1.

$$
\mathbf{P}_{\mathrm{T}}=\frac{\mathbf{L}_{\mathrm{T}}}{\frac{\mathrm{L}_{1}}{\mathbf{P}_{1}}+\frac{\mathbf{L}_{2}}{\mathbf{P}_{2}}+\ldots+\frac{\mathbf{L}_{\mathbf{n}}}{\mathbf{P}_{\mathbf{n}}}}
$$

$P_{T}$ is the total permeability and $L_{T}$ the total thickness of the bottle wall, whereas $P_{n}$ and $L_{n}$ are respectively the permeability and thickness of the $n$th layer. A common issue in multilayer applications is delamination. When the adhesion between the two polymers is unfavorable, the middle layer can become visible as it detaches from the structural layers during handling $[84,85]$.

Table 1. Oxygen permeabilities of common polymers in packaging.

\begin{tabular}{|c|c|c|}
\hline Barrier Polymer & $\begin{array}{c}\mathrm{O}_{2} \text { Permeability }\left(\mathrm{cm}^{3} \mathrm{~mm} \mathrm{~m}^{-2} \text { day }^{-1} \mathrm{~atm}^{-1}\right) \\
\text { RH } 50 \%, 23^{\circ} \mathrm{C}\end{array}$ & Source \\
\hline Polystyrene (PS) & $100-150$ & [4] \\
\hline Polyethylene (PE) & $50-200$ & {$[4]$} \\
\hline Polypropylene (PP) & $50-100$ & [4] \\
\hline Poly(lactic acid) (PLA) & 10 & {$[86]$} \\
\hline Poly(vinyl chloride) (PVC) & $2-8$ & [4] \\
\hline Poly(ethylene terephthalate) (PET) & $1-5$ & {$[4]$} \\
\hline Polyamide-6 (PA6) & 1,4 & {$[87]$} \\
\hline Poly(ethylene naphthalate) (PEN) & 0.5 & {$[4]$} \\
\hline poly(m-xylylene adipamide) (MXD6) & 0.05 & {$[88]$} \\
\hline Poly(vinyl alcohol) (PVOH) & $0.02-1$ & [89] \\
\hline Ethylene vinyl alcohol (EVOH) & $0.04-0,4$ & {$[86]$} \\
\hline Poly(vinylidene chloride) (PVDC) & $0.01-0,3$ & {$[4]$} \\
\hline
\end{tabular}

In films, this problem is solved by co-extruding tie-layers between the outer layers and the middle layer, consisting of an adhesive [90]. This is highly unfavorable in PET-bottles as this exhausts the recyclability of the polymer [85]. In other forms, a middle layer consisting of a polymer blend has been beneficial to limit the delamination effect. These blends usually exist of the targeted barrier polymer and a PET-copolymer [82,84]. Inorganic nano-compounds have also been shown to enhance the Vanderwaals-interactions between the layers [85].

While this multilayer solution has often been used in films, the desired specifications in bottles are often stricter as much longer shelf life is required. This passive barrier solution is not effective enough to reach the desired permeability for oxygen in bottle applications [83,91]. Multilayer structures in bottles are therefore mostly used for $\mathrm{CO}_{2}$-barriers, water vapor barriers or in combination with active barriers. For electronic applications, both water and oxygen barriers are required. Multilayer technologies that can combine both barriers are therefore highly recommended. However, organic passive barriers can never provide sufficient protection for oxygen, so at least some of the layers should consist of inorganic materials, such as those employed as coatings, discussed below [92-94].

\subsection{Coatings}

The coating of bottles can be seen as an alternative form of a multilayer technology. Instead of being sandwiched between two PET-layers, the barrier layer is now on the inner or outer surface of the bottle, but the same Equation (7) applies. These coatings can be both inorganic or organic.

Organic coatings that have been developed consist of thermosets like acrylics or epoxy-amine coatings $[95,96]$. They are usually coated on the outside with a thickness of approximately $50 \mu \mathrm{m}$ [97]. They typically improve the oxygen barrier by a factor of 2 . This usually does not suffice in most bottle applications, but can effectively be applied to films [4]. 
Thin silica coatings provide an excellent oxygen barrier, capable of reducing the diffusion through PET tenfold [4]. The silica is deposited by physical vapor deposition (PVD) or plasma-enhanced chemical vapor deposition (PECVD) on the inner bottle wall. Both processes lead to a thin layer with a thickness between $10 \mathrm{~nm}$ and $100 \mathrm{~nm}[98,99]$. The maximum thickness of the coating is limited with respect to food safety, color and flexibility. The same PECVD-technique can also be exerted with hydrocarbons to form a thin diamond-like carbon layer $[53,100]$. Both coatings have very good performances, but require high investment costs and have limited flexibility and crack resistance [98,101]. Table 2 shows the permeabilities of the different coatings with respect to oxygen.

As stated above, combinations between coating and multilayer is possible as well. Current flexible OLED-solutions for example exist of a combination of coatings in a multilayer structure. Typically, PET is coated with inorganic layers that are separated by organic adhesives (acrylates). This provides a decent oxygen barrier, but also a very good water barrier, which is often even more critical in organic electronics [102].

Table 2. Oxygen permeabilities of common coatings in packaging.

\begin{tabular}{|c|c|c|}
\hline Coating Layer & $\begin{array}{c}\mathrm{O}_{2} \text { Permeability }\left(\mathrm{cm}^{3} \mathrm{~mm} \mathrm{~m}^{-2} \mathrm{day}^{-1} \mathrm{~atm}^{-1}\right) \\
\mathrm{RH} 50 \%, 23^{\circ} \mathrm{C}\end{array}$ & Source \\
\hline Epoxy-amine & $0.2-1.3$ & [97] \\
\hline Diamond-like Carbon (DLC) & 0.005 & [103] \\
\hline Silicon oxide $\left(\mathrm{SiO}_{\mathrm{x}}\right)$ & $1-3 \times 10^{-5}$ & {$[104,105]$} \\
\hline
\end{tabular}

\subsection{Composites}

Multilayered technologies all require specific equipment, adding up to the total cost. Many research groups are therefore focusing on the improvement of the passive barrier in monolayer systems. The main polymer will therefore need to be intrinsically modified. Blending in a barrier polymer such as the nylon poly(m-xylene adipamide) (MXD6) has been proven to be effective as an oxygen barrier at concentrations starting from $10 \mathrm{wt} \%[88,106]$. MXD6 is immiscible in PET, forming micron-sized islands. The oxygen that attempts to enter the bottle will encounter a high tortuosity, increasing the diffusion pathway. The effect on solubility is minimal, but the diffusion can be halved in a blend of $10 \mathrm{wt} \%$ MXD6 [106].

Several research groups have attempted to formulate a relation between modifier concentration and permeability. This led to variable mathematical models that have been widely discussed in other reviews. The most basic model equation is only briefly presented here and the reader is referred to more in-depth reviews for further information [107-109]. Most models are derived from Maxwell's equation for electrical conduction through a heterogeneous medium. Herein, a tortuosity factor $\tau$ can be introduced to account for the increase in path length [110-112].

This factor can be related to the volume fraction of an additive present as spherical particles by following Equation (8) [80,106].

$$
\frac{\mathbf{P}_{\text {Blend }}}{\mathbf{P}_{\mathrm{PET}}}=1+\frac{3 \phi}{\frac{\mathrm{R}+2}{\mathrm{R}-1}-\phi}=\frac{1-\phi}{\tau}
$$

With $\mathrm{P}_{\text {blend }}$ the permeability of the blend, $\Phi$ the volume fraction of the barrier polymer and $\mathrm{R}$ the ratio $\mathrm{P}_{\mathrm{i}} / \mathrm{P}_{\mathrm{PET}}, \mathrm{P}_{\mathrm{i}}$ being the permeability of the pure barrier polymer. In both films and bottles, a stretch is induced on the blend when processed. This will alter the particle configuration to an ellipsoidal structure with the longitudinal axes following the stretch direction. Diffusion through the wall occurs perpendicular to this stretch, so the particles appear much larger to the diffusing compound, providing the most efficient increase of tortuosity. This factor needs to be considered in the equation. Additionally, the equation can be simplified as $P_{i}$ tends to be much lower than $P_{\mathrm{PET}}$ in order to be relevant. $R$ in 
Equation (8) will then approximate the value of 0 . Nielsen has implemented both alterations to provide Equation (9) as an estimation for the tortuosity in blends [113].

$$
\frac{\mathbf{P}_{\text {Blend }}}{\mathbf{P}_{\mathrm{PET}}}=\frac{1-\phi}{1+\frac{\alpha \phi}{2}}=\frac{1-\phi}{\tau} \text { with } \alpha=\frac{3}{2} \lambda^{3}
$$

With $\lambda$ the axial aspect ratio (axial length/hoop length of the ellipsoid).

Other models are often adapted to more specific conditions. For example, Bruggeman's model is most fitted for polymer blends with very similar permeabilities [114].

In PET, the popularity of nylon MXD6 yields from it owning a similar refractive index as PET. The immiscibility of MXD6 in unstretched PET will not lead to light refraction. However, stretching will induce a change in refractive indices in a ratio that is different for each polymer and will lead to a high haze-level in the product. This diminishes the attractiveness of the product to the customer [88,115]. Several inventions have been filed to reduce the effect by increasing the affinity of the two polymers (covalently or electrostatically), reducing the island size to nano-sized structures that interfere much less with visible light [58,116-118].

A similar approach to the improvement of oxygen retention in PET is to blend in inorganic nano-particles. The structure of the particles is relatively inert to the PET-processing, consistently providing low haze $[119,120]$. Additionally, these solid fillers will provide for a lower free volume in the PET, lowering the solubility of oxygen in the composite material as well $[87,89]$. There have been multiple developments in this area with fillers of $1 \mathrm{~nm}$ thickness and 100-1000 $\mathrm{nm}$ in diameter. In these dimensions, interference with light is minimal, offering an improvement in haze to conventional polymer blends. A platelet-form is preferred to achieve very high aspect ratios in Equation (9). Clays are very popular as the fillers in these systems, but also graphene and silicates have been investigated [121-124].

Despite the inert nature of these particles to the process, these systems are still struggling with dispersion and orientation of the particles. The layered particles prefer stacking, even when processed in PET. Certain techniques for impregnating the particles into the polymer can cause the platelets to separate into differing compositions. In order to be effective as a barrier, the particles should be spread out (exfoliated) and should be oriented in parallel to the stretching of the polymer, similar to MXD6 after deformation [125-127].

In addition to external fillers, the strategy of increasing tortuosity has been found to proceed even with PET itself. Crystallization of the structural polymer can be induced by entering nucleating agents to create dense areas, lowering solubility and diffusion of gases as well [56,128].

So far, this is still an emerging technology and has not yet reached high commercial successes. However, oxygen transmission rates below that of SiOx-coatings have been achieved by a multilayered barrier with exfoliated nano-clays and therefore shows great promise. The barrier performance for both oxygen and water still needs to be improved though to reach the strict requirements for the electronics applications. Additionally, some areas of the visible light are still absorbed by the film, which also requires optimization [129].

\section{Active Barriers}

For many applications, any contact with oxygen, even small concentrations, is undesirable during the shelf life of a packaged product. Passive barriers often do not comply with these specifications. Incorporating highly oxygen-sensitive compounds to the packaging might provide a solution by chemically reacting with oxygen, removing its oxidizing nature and providing an "active oxygen barrier". Such a substance can be implemented into the packaging by several methods, shown in Figure 8 . However, not every active barrier can be incorporated by each method. 
a)

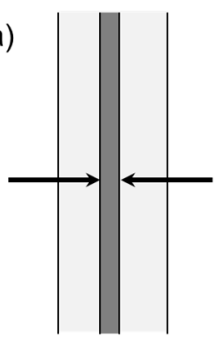

b)

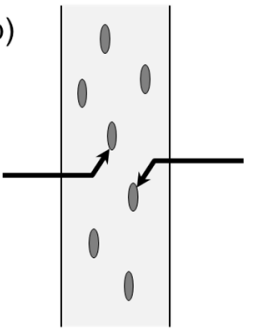

c)

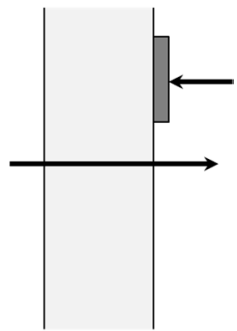

Figure 8. Three strategies to incorporate an active oxygen scavenger material (dark color) to a structural polymer (light color): Multilayer (a), blending (b) and as a pouch (c). The solid arrow represents the oxygen flow. For each drawing, outside of the packaging is left, while the inner content is given on the right side.

Solutions such as multilayer or blending may provide both a passive and an active barrier. However, the passive barrier usually can be neglected in comparison to the active scavenging. This is especially the case in an active blend, where the concentration of barrier polymer is usually much lower to limit hazing due to immiscibility. Usually, the oxygen flux from the outside of the bottle wall is zero or even negative in these systems. A reaction rate needs to be added to Equation (6), leading to Equation (10) [130].

$$
\mathbf{Q}_{\text {package }}=\int_{\mathbf{A}} \frac{\mathbf{P}}{\mathbf{L}} \sigma\left(\mathbf{p}_{\mathrm{O}_{2, \text { outside }}}-\mathbf{p}_{\mathrm{O}_{2, \text { inside }}}\right)-\mathbf{r}_{\mathrm{OS}} \mathbf{d} \sigma
$$

With $\mathrm{r}_{\mathrm{OS}}$ the reaction rate of the oxygen scavenger within a surface area of the package $\left(\mathrm{cm}^{3}\right.$ oxygen scavenged $\mathrm{m}^{-2} \mathrm{day}^{-1}$ ). For highly active scavengers, the reaction rate is often limited by its access to oxygen in the wall. The rate can therefore be indirectly related to permeability, but permeability is unaffected by the activity of the scavenger. Expressing the active barrier performance in terms of measured permeability or OTR data is therefore incorrect. However, this is a very common mistake. Another approach to incorporating active barriers to packaging is capturing the oxygen scavenger in a pouch or sticker, usually consisting of a silica gel matrix that can be glued to the inner wall or the cap.

The pouch is most often placed in the headspace, as Henry's law states that oxygen is preferably in the gas phase. While the oxygen content in the headspace is lowered, the concentration in the product will follow this trend through Henry's law. Oxygen flux through the bottle wall is now completely separated from reaction rate so the volume of oxygen in the contents of the bottle, $V_{\text {in }}\left(\mathrm{cm}^{3}\right)$, changes in time according to Equation (11).

$$
\frac{\mathrm{dV}_{\text {in }}}{\mathrm{dt}}=\mathrm{Q}_{\text {package }}-\mathrm{r}_{\mathrm{OS}, \text { total }}=\int_{\mathrm{A}} \frac{\mathrm{P}}{\mathrm{L}} \boldsymbol{\sigma}\left(\mathrm{p}_{\mathrm{O}_{2, \text { outside }}}-\mathrm{p}_{\mathrm{O}_{2, \text { inside }}}\right) \mathrm{d} \sigma-\mathrm{r}_{\mathrm{OS}, \text { total }}
$$

The scavenger reaction rate in the equation now covers the total scavenging rate $\left(\mathrm{cm}^{3}\right.$ oxygen scavenged $\mathrm{day}^{-1}$ ) and is dependent on the oxygen content in the product itself instead of the oxygen content in the wall.

The applications with pouches are very popular in Asia, but are still limited in Western countries due to the food safety regulations that prohibit their use in beverages. Aside from regulatory aspects, the visual appearance of the pouch is often unattractive towards the consumer [131].

Given how the reaction rate is usually dependent on the bottle constitution, it is very difficult to compare different literature values as quantification for the active barrier efficiency. Many active barriers are activated by water, so only analysis techniques that allow contact between water and the barrier material can provide sufficient information. Many techniques however do not or only partly offer humidification (see Section 2.2). Additionally, it is safe to assume that for all active barrier techniques that have an overall reaction rate larger than the permeability term, there will be overall 
no oxygen build-up in the packaging until the reaction is exhausted. Published OTR-values therefore only have limited use as a qualifier.

There are multiple types of oxygen scavengers on the market or in development. They may provide a reaction of oxygen with solely an organic scavenger, but more often an inorganic metal is involved, either as a substrate or as a catalyst [132]. Other active packaging constructs are also on the market, containing polymer-grafted enzymes and metal-chelating groups. They are however not removing oxygen, but are slowing down the radicalar oxidation reactions in food [6,133]. They will therefore not be further discussed in this publication. Active barriers have not yet been widely implemented in electronic applications so far, but results by Amberg-Schwab et al. suggest that these materials could create great value as zero transmission laminates [14].

\subsection{Antioxidants}

For many years, sulphites have been added to wines as a protection for polyphenols during its aging in barrels [48]. Sulphites readily react with oxygen to form stable sulphates, inhibiting propagation in the radical chain of oxidative degradation in the wine. This technique is self-explanatory and has been translated to some packaging constructs [134]. Sulphites, but also ascorbic acid, $\alpha$-tocopherol (vitamins $C$ and $E$ ) and phosphites can be applied as part of the packaging material or in the form of a pouch or sticker [15,135-137].

Within this category, vitamin $C$ is the most popular scavenger since adding a food component to the packaging immediately implies food contact compliance. Even though the degradation phenomena involving ascorbic acid are relatively complicated, much research on this subject has been performed [138-140]. A schematic representation is shown in Figure 9. It is important to note that these reactions are described as they occur in juices. Oxidation as a packaging additive might occur slightly different.

The degradation of vitamin $C$ can occur both aerobic and anaerobic, but the aerobic oxidation reaction has faster kinetics. It can react with reactive oxygen species (photo-initiated or heat-initiated in packaging processing) via two one-electron exchanges to dehydroascorbic acid (DHA) with mono-dehydroascorbic acid as the intermediate in an easily reversible reaction. Depending on the radical count in the matrix, the flexibility of the stabilized intermediate radical structure can provide either an antioxidative, quenching other radicals by forming DHA, or a prooxidative nature, abstracting hydrogen from non-radical organics and forming L-AA [141-143].
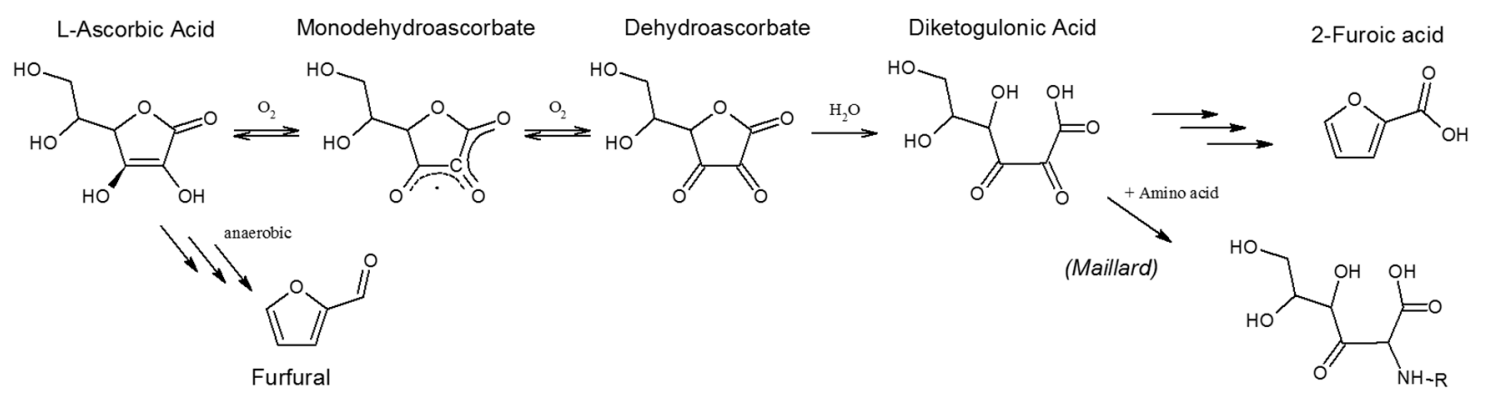

Figure 9. Degradation mechanism of L-Ascorbic Acid in fruit juice [15].

Instead of reverting back to L-AA, DHA can also undergo a hydrolysis reaction, forming 2,3-diketogulonic acid through ring cleavage. The resulting acid exhibits further degradation towards the brown-colored 2-furoic acid and 3-hydroxy-2-pyrone [144,145]. Under anaerobic and acid conditions, L-AA may also slowly hydrolyze in a ring-cleavage, degrading to furfural, which also incites a brown coloration $[138,139]$. In order to accelerate the scavenging, sometimes a transition metal Fenton-catalyst, as explained in Section 2.1, is added to vitamin-containing compositions to increase the oxidation rate. However, this is usually not an effective barrier in comparison to other 
active barriers $[146,147]$. This technology is therefore not often employed and will also not achieve the requirements for the emerging application fields.

\subsection{Iron-Based}

A form of oxidation that is well-known to anyone, is the rusting of iron. It therefore seems obvious that this mechanism could be employed as an oxygen scavenger in packaging as well. Iron particles are added to a packaging, mostly in a pouch form [148]. Added as a blend in the polymer, it will usually lead to the visual appearance of the particles in the packaging [149]. Recently however, there have been researches that claim to resolve this issue by adsorbing iron nanoparticles on nano-sized clays in order to provide both the active and passive barrier [150]. While for commercial systems, the discoloration will prove application in organic electronics highly unlikely, the development of this nano-technology may open up some possibilities in this field.

The oxidation chemistry of iron is given by reactions (12)-(14). Metallic iron can donate 2 electrons in an anodic reaction. The layer of water surrounding the iron particles acts as the electrolyte to provide oxygen with the electrons and form hydroxides in water as the cathodic reaction. The released iron ions may then be ligated in solution to form iron(II) hydroxides.

Further oxidation of the iron will ultimately provide trivalent hydroxide species that can recombine by dehydration, forming the red iron oxide $\mathrm{Fe}_{2} \mathrm{O}_{3}$ [151].

$$
\begin{gathered}
\mathrm{Fe}^{(0)}+2 \mathrm{H}_{2} \mathrm{O} \rightarrow \mathrm{Fe}^{(\mathrm{II})}(\mathrm{OH})_{2}+2 \mathrm{e}^{-}+2 \mathrm{H}^{+} \\
\mathrm{H}_{2} \mathrm{O}+\frac{1}{2} \mathrm{O}_{2}+2 \mathrm{e}^{-} \rightarrow 2 \mathrm{OH}^{-} \\
2 \mathrm{Fe}^{(\mathrm{II})}(\mathrm{OH})_{2}+2 \mathrm{H}_{2} \mathrm{O}+\mathrm{O}_{2} \rightarrow \mathrm{Fe}_{2} \mathrm{O}_{3} \cdot 3 \mathrm{H}_{2} \mathrm{O}
\end{gathered}
$$

Eventually, the deposited oxide will envelop the metal particles, preventing oxygen diffusion to the reduced bulk iron particles and halting oxygen uptake [152].

The scavenger composition can be altered to accommodate for a faster reaction rate. Reaction 13 can be favored by addition of an acidifying component. Oxygen reduction requires both a proton and an electron so adequate dissociation of water is preferred. Additionally, an extra electrolyte in contact with the iron will also accelerate the oxygen uptake by enhancing the electron transfer [153-155]. High surface areas are preferred in this reaction, increasing scavenging rate and time before deactivation. Nano-sized iron particles have been found favorable over the traditional micron-sized powders [151]. For food applications however, this is not accepted due to the toxicity of such nanoparticles. As an advantage to iron-based scavengers, the water requirement in the reaction will provide that the iron will achieve low activities during the empty shelf life period, but will start to oxidize mainly after the filling of the bottle.

\subsection{Pd/Pt-Based}

A recent development in the area of active oxygen barriers is based on fuel cell technology: Oxygen is reduced by hydrogen to form water [156]. The barrier consists of two distinct parts. First, hydrogen needs to be present. The atmosphere can be modified to hold high pressures of molecular hydrogen, but in most cases, a controlled release of hydrogen was chosen by incorporating hydrogen-evolving compounds. Examples of these compounds exist of calciumhydride or sodium borohydride, incorporated in the bottle cap [156-158]. As soon as the bottle is filled and water vapor enters the cap, hydrogen is set free through reaction (15) [159,160]. The capacity of the barrier is again not very affected by the dry empty shelf life. In bottle technologies, the hydrogen-evolving compounds can be easily incorporated in the cap. For film applications however, especially for OLED-materials, its insertion in the system will provide more difficulty.

$$
\mathrm{NaBH}_{4}+2 \mathrm{H}_{2} \mathrm{O} \rightarrow \mathrm{NaBO}_{2}+4 \mathrm{H}_{2}
$$


The reaction between hydrogen and oxygen can be split into two reactions: the oxygen reduction reaction (ORR) and the hydrogen oxidation reaction (HOR). Both require a catalyst that is usually a precious metal, such as for instance $\mathrm{Pd}$ and $\mathrm{Pt}$ that are the most recurring metals herein [161-163]. When compounded into a packaging solution, the catalyst is usually added as a divalent acetate salt, but it has been stated that at processing temperatures, the metal ion is reduced by its ligand to zero-valent metal particles and $\mathrm{CO}_{2}$. The nano-sized metallic particles provide an active surface for reaction [164]. Ultimately, the metal can also be introduced as pre-formed nano-particles [165]. It has been widely examined how surface morphology of such particles effect the reactions, so well-defined structures would be able to improve the catalyst efficiency [166-168].

The exact reaction mechanisms are still disputed, but are highly investigated in contact with watery solutions. For the HOR, it is assumed that hydrogen is adsorbed to the surface of the catalyst by dissociation, either to atoms (Equation (16)) or to an atom and an ion (Equation (17)). This is quickly followed by a charge transfer, releasing electrons in the conductance band of the metal (Equation (18)). These reactions are respectively referred to as the Tafel reaction, Heyrovsky reaction and the Volmer reaction $[166,167]$.

$$
\begin{gathered}
2 \mathbf{P t}+\mathbf{H}_{2} \rightarrow 2 \mathbf{P t}-\mathbf{H} \\
\mathbf{P t}+\mathbf{H}_{2} \rightarrow \mathbf{P t}-\mathbf{H}+\mathbf{H}^{+}+\mathbf{e}^{-} \\
\mathbf{P t}-\mathbf{H} \rightarrow \mathbf{P t}+\mathbf{H}^{+}+\mathbf{e}^{-}
\end{gathered}
$$

On the side of ORR, the reaction is assumed to proceed either via a direct reduction with 4 electrons or through the formation of an intermediate hydrogen peroxide species (see Figure 10) [163,167]. This species can form water with the addition of two more electrons, be decomposed on the surface or can be released as an oxidizing component in the solution.

This system has been found to achieve very good performances, but the high cost of both the catalyst and the hydrogen source have limited the commercialization of the technology [169].

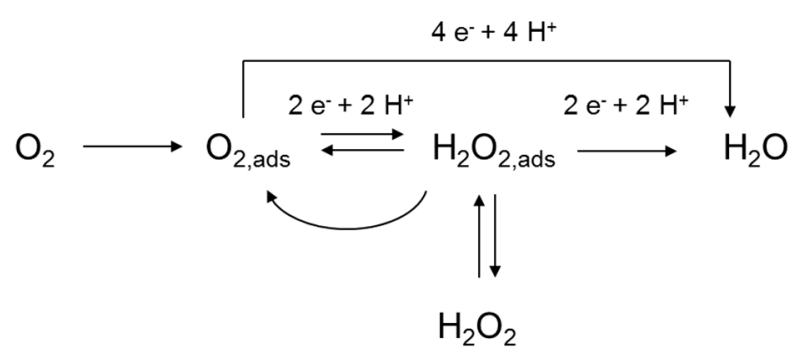

Figure 10. Simplified scheme for the ORR reaction pathways.

\subsection{Co-Based}

The catalytic activities of middle to late transition metal ions ( $\mathrm{Fe}, \mathrm{Cu}, \mathrm{Co}, \mathrm{Mn}$, etc.) in oxidation reactions have been mentioned already in Section 2.1. The catalytic disproportionation of peroxide-species to highly active hydroxyl radicals is catalyzed in Fenton-like reactions (Equations (1) and (2)). This mechanism is widely attributed to the degradation of organics in watery solutions [32].

In the late 1980s, Cochran discovered that the oxidation of polymers such as MXD6 in blends could also be catalyzed by cobalt ions in what was stated to be a similar mechanism [170-172].

Deperoxidation in an aqueous environment may be catalyzed by a series of 4 th row metals from $\mathrm{Mn}$ to $\mathrm{Cu}$ with a leading role for iron. However, in polymeric blends cobalt has always been noted as the preferred metal $[31,173]$. Scavengers with other metals such as manganese have only been reported sporadically and with significant lower activity [174].

In addition, the oxygen scavenging process can show very different behaviors for different substrates. Currently, there are two major substrate types that cover almost the entire market for active oxygen barriers. The first group exists of polyamide sacrificials with MXD6 as a typical representative. 
The second type of sacrificial compounds provide an unsaturated bond as the reactive site with poly(1,3-butadiene) (PBD) as a leading example. Other polymers such as polyketones and polyethers have all also been reported to possess oxygen scavenging capabilities, but have not yet been highly commercialized nor investigated [175,176].

\subsubsection{Polyamide Sacrificials}

MXD6 was the first polymer that was employed for its scavenging ability [170]. It has already been discussed as a passive barrier in PET, both as a blend and a multilayer. The polymer owes its popularity to similar thermal and rheological properties compared to PET, which is beneficial for the processing of a PET-MXD6 combination. Additionally, the low permeability for gases would enhance the functionality as a passive barrier, both for oxygen and $\mathrm{CO}_{2}$. The disadvantage of haze creation in blends has already been stated in Section 3.3. Additionally, another downside to MXD6 is the potential yellowing effect on the final packaging. At high processing temperatures, a discoloration has been assigned to the condensation of aldehyde-groups to amine end-groups, forming azomethine-groups and eventually creating a conjugated oligoenimine structure, yielding the typical yellow color. The concerning aldehydes can be generated by either oxidation of the polyamide itself or the acetaldehyde elimination of PET $[177,178]$. The consequence of this effect is that nylon blends are not recyclable and all MXD6 has to be removed prior to post-consumption solid state polycondensation, leading to higher recycling costs.

The autoxidation reactions of polyamides as MXD6 have been investigated to a wide extent $[171,172,178]$. Under the influence of temperature, light or certain transition metal ions, activated oxygen will be able to attack the polymer chain, creating organic radicals. The $\alpha$-carbon to the amide functionalities has been identified to be the main site of $\mathrm{H}$-abstraction due to conjugation of the radicalar charge [172,178].

Figure 11 provides visual representation of the initiation (a) and the following breakdown reactions $(b-i)$. Propagation may continue through a variety of parallel reactions. After H-abstraction, the organic radical species $\left(\mathrm{R}^{\circ}\right)$ provides a high affinity for capturing triplet oxygen and forming a peroxyl group $\left(\mathrm{ROO}^{\circ}\right)(\mathrm{b})$. This peroxyl group in turn abstracts another hydrogen atom from an unreacted functional site $(\mathrm{RH})$, propagating the chain to both a peroxide $(\mathrm{ROOH})$ and a new organic radical (c). On the other hand, when the peroxyl-radical $\left(\mathrm{ROO}^{\circ}\right)$ encounters an organic radical before it has captured molecular oxygen, termination may occur, leading to the creation of an $\mathrm{N}$-carbonylimine (d), able to later undergo hydratation to an alcohol. Additionally, peroxyl radicals can recombine with each other or stable peroxide functionalities to create a variety of different products, conform the exemplary decay mechanism in Section 2.1 (Figure 5). After recombination or Fenton-catalysis of peroxide groups, the $\mathrm{O}-\mathrm{O}$ bond splits. Oxyl radicals are formed $\left(\mathrm{R}-\mathrm{O}^{\circ}\right)$ that will again lead to multiple pathways, depending on the available functionalities in their environment (e). Whereas the oxyl function could be the target of an $\mathrm{H}$-abstraction, forming an imide function (f), it could also be the acting $\mathrm{H}$-abstractor to create an alcohol (g).

Additionally, $\beta$-scissions are also common in oxyl-decay. An internal electronic shift will break the bond next to the oxyl-function. For MXD6 this is usually the weaker C-N bond (h), but the side of the aromatic ring is also possible (i). Scissions usually lead to aldehyde formation, even though these aldehydes can also oxidize further to carboxylic acid functions [171,172,178].

The role of cobalt is still very unclear. Patel and Ball have both examined the oxidation of MXD6 as an oxygen scavenger in PET and found that Co is immobile in the polymer blend [171,172]. The immobility of cobalt should eliminate all pathways where cobalt requires direct contact with the reactive site of the polyamide in the catalytic cycle.

This is where the two researchers disagree on whether Co will be either an initiation catalyst, a propagation catalyst or both. The discussion is fueled by the suggested ligation of cobalt to MXD6. Research by Cochran has indicated that Co could complex with MXD6, while other metals could not [171]. Figure 12 shows the proposed formation of a complex between the nylon and the cobalt and 
its assumed activity as an initiating catalyst. Cobalt captures and activates triplet oxygen by reducing it to a superoxide. As a propagation catalyst, it is assumed to perform deperoxidations, following the Fenton reaction (Equation (2)) [171,172].

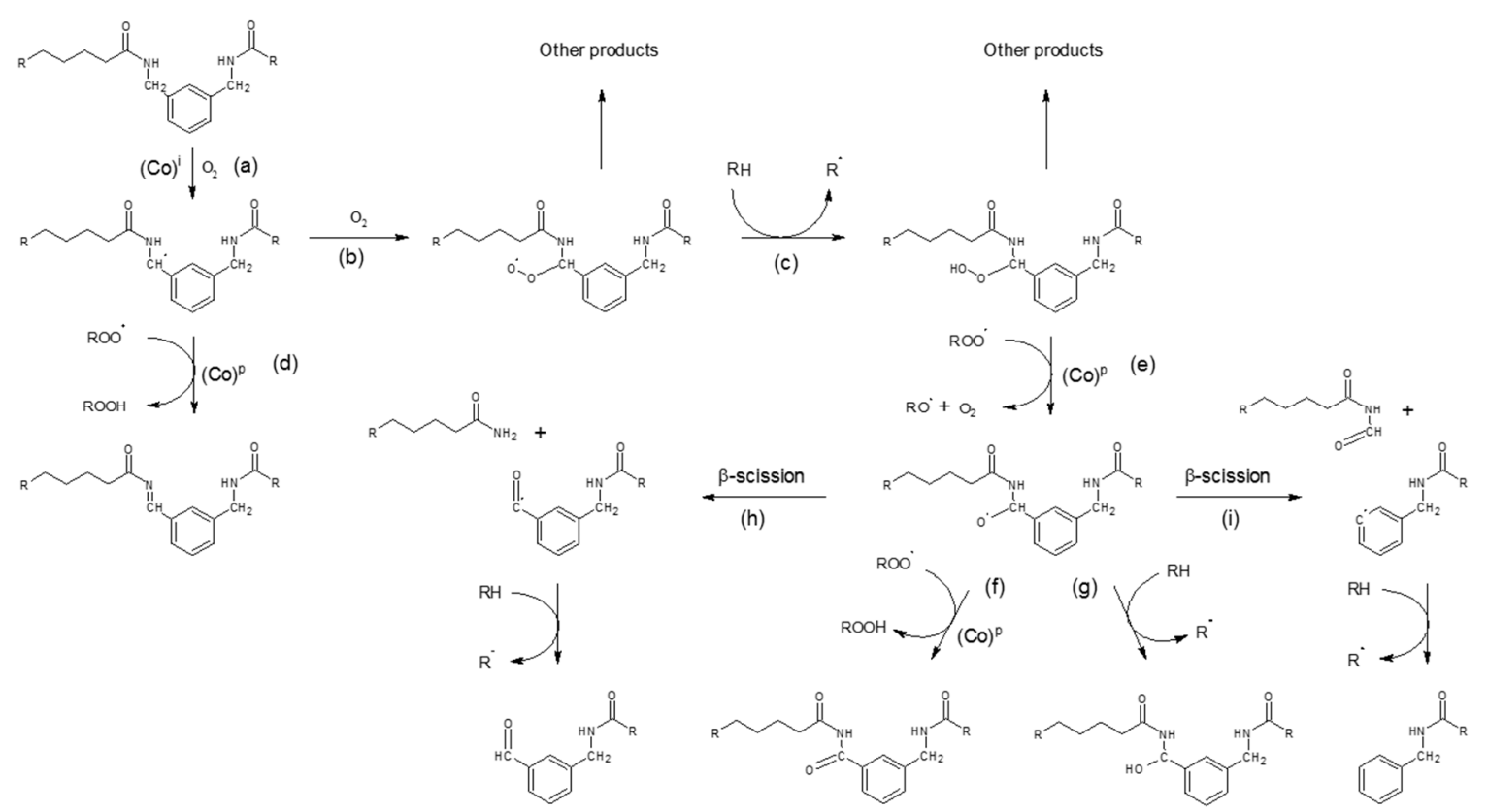

Figure 11. Possible oxidation mechanisms for poly(m-xylylene adipamide) (MXD6). Only a limited amount of possibilities is shown due to the complexity of the radicalar mechanism. The different steps have been named (a-i) as a reference to the text. The steps where cobalt might be present as a catalyst have been marked with (Co), with $\mathrm{i}$ as an initiation catalyst and $\mathrm{p}$ as a propagation catalyst $[171,172,178]$.<smiles></smiles>

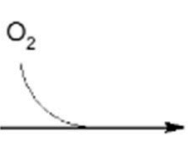<smiles></smiles><smiles>[R]CCCCC(=O)NCc1cccc(/C=N/C([2H])=O)c1</smiles>

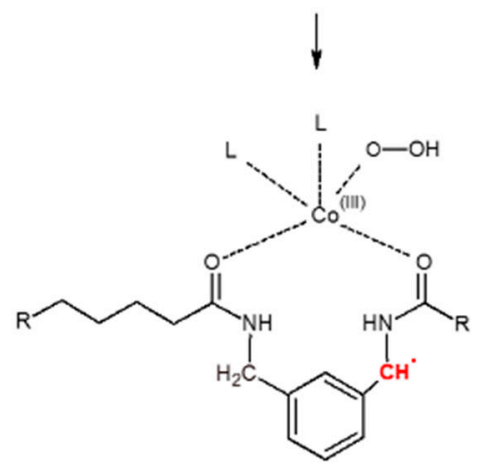

Figure 12. Proposed mechanism of cobalt as initiation catalyst for nylon MXD6 oxidation [172]. 
Several patents state the presence of an induction time on the reaction $[118,179]$. Conform to the autoxidation hypothesis, this has been suggested to be due to the initial build-up of hydrogen peroxide before the subsequent propagation phase.

Multiple successful attempts have been made to lower this induction time by adding extra photosensitizers or charging the polymer with highly energetic radiation [58,180-183]. All of these solutions are intended to boost radical initiation.

Recently, low molecular weight variants of MXD6 have been marketed. These monomeric components are much better distributed inside the PET-matrix. The result of this new technology is the manufacture of clear bottles without any loss in oxygen scavenging [184-186]. To provide visually appealing bottles with high activity otherwise, MXD6 can be processed as a multilayer solution with a completely clear wall. This production method is more expensive than the monolayer version, but it is possible to add a much higher sacrificial content in the active layer, providing a scavenging capacity ranging over multiple years [82,187]. For this reason, it is a very attractive barrier for further development in the high-end application fields. Organic electronics can be protected with zero oxygen ingress and as films of more than three layers can easily be manufactured, higher concentrations than in bottles may be employed. The main issue here will be the simultaneous protection against water vapor since these barrier types require water for their scavenging reaction. A well-defined organization of the layered materials will be necessary.

\subsubsection{Unsaturated (Co-)Polymer Sacrificials}

As a reaction to Cochran's polyamide solution, several alternatives came onto the market carrying polydienes and other unsaturated sacrificials. In contrast to MXD6, the oxygen scavenging for unsaturated compounds has been found to not entail an induction phase; instead the compounds are able to immediately capture oxygen. However, the total capacity per active site appears to be much smaller, so only shorter shelf lives can be achieved with this functional barrier. In-house experiments have shown that in the case of bottle technologies, commercial oxygen scavenging containers with polyamides are able to obtain shelf lives where oxygen will not exceed degradative concentrations of 6 months to several years. Commercial PBD-functionalized containers are shown to obtain 1-8 months of oxygen-free content $[188,189]$. There have so far been no publications explaining these differences, but it is often assumed that the high scavenging activity will exhaust the capacity already during injection and/or empty shelf life.

The general mechanism of polybutadiene oxidation is very similar to MXD6. A hydrogen abstraction is also the most accepted initiation for the polymer. Moreover, PBD is reported to be more susceptible to initiation than polyamides [190]. It is possible that this hails from the generation of singlet oxygen during early stages of oxidation, which is highly selective towards unsaturated compounds as seen in Section 2.1. Further radical propagation through the same mechanism as MXD6 will eventually lead to carbonylation or $\beta$-scission. There also have been reports of additional propagation steps for PBD. Firstly, the presence of conjugating double bonds next to the hydrogen-abstracted methylene can transfer the radical along the chain to realize many different arrangements. Aside from this, reports also state the occurrence of epoxidations and intermolecular additions in PBD degradation [191-195]. These additions cause PBD to have a much wider range of degradation pathways and products as MXD6 of which some have been listed in Figure 13.

The immiscibility of PET and nylon has already been proven to be the limitation to the concentrations due to its hazy look. The blending of highly hydrophobic olefins such as PBD will evidently suffer the same consequences. Effectively, the mass-based concentrations of PBD in PET are claimed to be much lower than of MXD6 for the acceptable visual appearance. Increasing the interactions between the two polymers is actually indispensable $[189,196]$. One improvement for this problem has been to bind the PBD covalently to PET. The addition of anhydrides (especially maleic anhydride) or epoxide-containing polymers is common in this area $[188,197]$. The PBD itself can be functionalized before injection as evidenced by the broad application of hydroxyl-terminated 
polybutadiene (HTPBD). These end groups can enter in the polycondensation of PET by reacting with carboxylic end groups and producing a block-co-polymer [192,196]. Other inventions attempt to bypass PBD altogether by implementing unsaturated sacrificials with higher hydrophilicity. Polyesters from terephthalic acid and unsaturated diol monomers are produced for this cause. Examples are cyclohexenyl diol and 2-butene 1,4-diol [198,199]. These types of molecules have also been linked to inorganic materials by silylation as part of a multilayered structure for OLED protection [14]. It has therefore already proven its merit in these applications, but the water-dependence of the reaction should also be an issue here. Further investigation will prove valuable here as well, even though the amide-based barriers are known to own higher capacities.

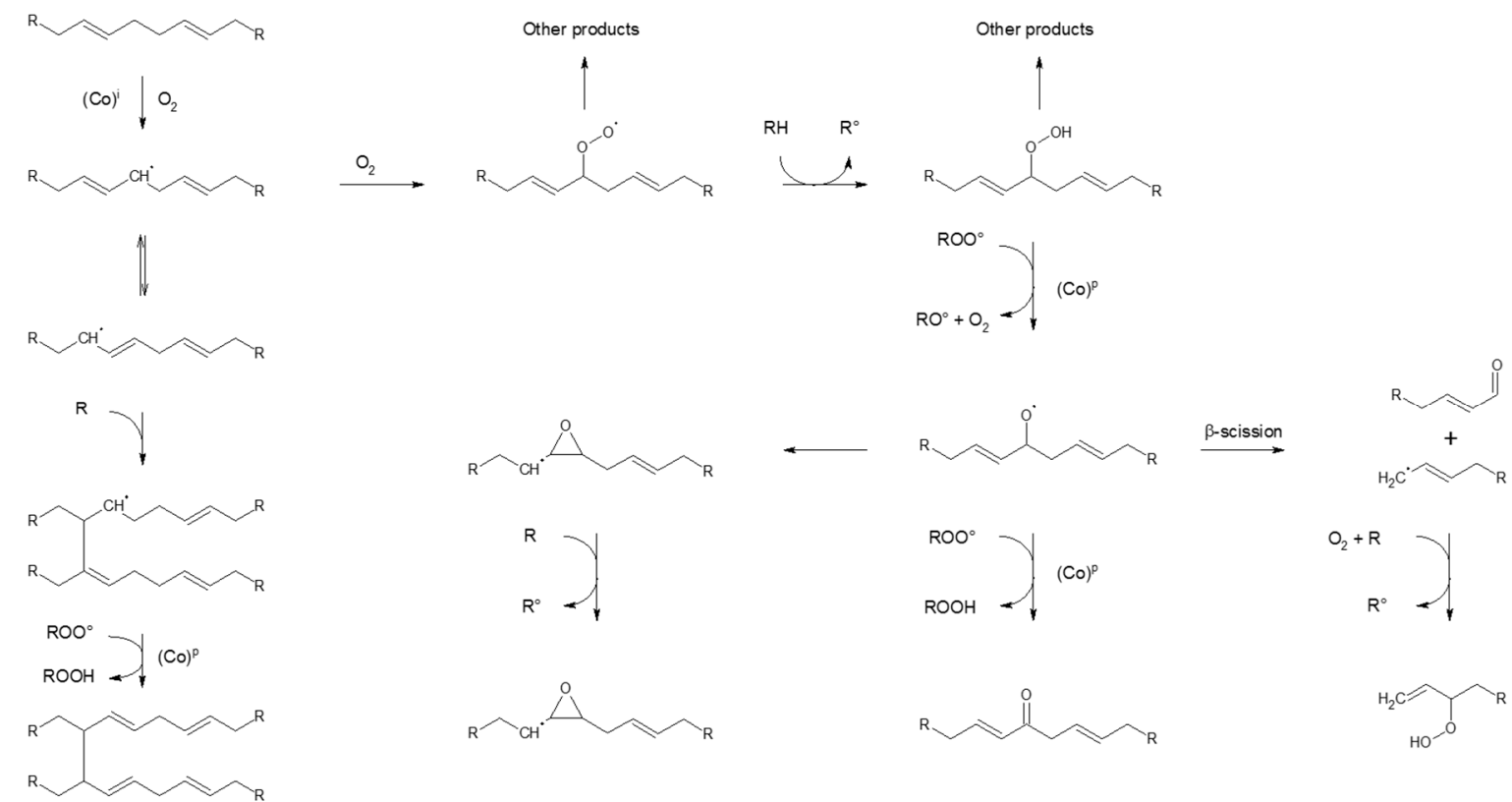

Figure 13. Examples of oxidative degradation pathways for poly(1,3-butadiene) (PBD). The steps where cobalt might be present as a catalyst have been marked with (Co), with $i$ as an initiation catalyst and $\mathrm{p}$ as a propagation catalyst [191-195].

\section{Prospectives}

Oxygen barriers for plastic packaging have been around for decades. Pressured by the great need for food packaging with oxygen retention, the patent literature on the subject has been flooded with inventions from industrial researchers. Nevertheless, the most commercialized oxygen barriers have barely changed since the 1990s. The need for innovation is now greater than ever as new applications arise in electronics and photovoltaics. Additionally, food packaging barriers still have a lot of major issues to solve.

Environmentally aware customers are getting more critical to what they consume or throw away. Increasing restrictions on food contact regulations, higher demands for recycled material and lightweighting, higher clarity requirements, these are all important drivers to be taken into consideration for the packaging community.

The most performant and most accepted oxygen barrier on the market now consists of the nylon and cobalt based active barrier technology. This composition can provide the longest shelf life for agreeable costs. The technique is however still lacking in the visual appearance and recyclability due to the nylon MXD6. Other sacrificials with similar activities, but improved functionalities, can quickly attract very important customers.

Improvement of these active barriers would require the solving of many unanswered questions on the chemical side of the scavenging systems and especially towards the catalytic mechanism. 
Fundamental investigations are necessary in order to develop new materials in a directed way. Towards future barrier systems, the catalyst will also tend to become more important as an innovation pathway since in 2013, three cobalt salts have been banned from food contact materials. This has stained the reputation of cobalt and an adequate replacement for this metal will soon need to be found.

In the emerging fields of organic electronics, there are even more obstacles to be overcome. The increase of barrier lifetime is always a highly valued property and when taking into account the electronics application, it will most certainly become a must as passive barriers will not likely be able to provide a clear and flexible solution to this end. The major issue however is that these electronic components are also sensitive to degradation by water, while most active oxygen barriers are only able to scavenge in highly humid environments. It will be absolutely necessary to optimize a design with multiple layers in order to produce a flexible cover that protects the organic semi-conductors on all fronts.

Acknowledgments: This study was supported by Flanders Innovation \& Entrepreneurship (VLAIO) by means of a Baekeland mandate.

Author Contributions: Youri Michiels wrote the paper. Peter Van Puyvelde and Bert Sels have reviewed and critiqued the manuscript.

Conflicts of Interest: The authors declare no conflicts of interest.

\section{References}

1. Amienyo, D.; Gujba, H.; Stichnothe, H.; Azapagic, A. Life cycle environmental impacts of carbonated soft drinks. Int. J. Life Cycle Assess. 2013, 18, 77-92. [CrossRef]

2. Accorsi, R.; Cascini, A.; Ferrari, E.; Manzini, R.; Pareschi, A.; Versari, L. Life cycle assessment of an extra-virgin olive oil supply chain. In Proceedings of the 18th Summer School "Francesco Turco"—-Industrial Mechanical Plants, Senigallia, Italy, 11-13 September 2013; pp. 172-178.

3. Humbert, S.; Rossi, V.; Margni, M.; Jolliet, O.; Loerincik, Y. Life cycle assessment of two baby food packaging alternatives: Glass jars vs. plastic pots. Int. J. Life Cycle Assess. 2009, 14, 95-106. [CrossRef]

4. Lange, J.; Wyser, Y. Recent innovations in barrier technologies for plastic packaging-A review. Packag. Technol. Sci. 2003, 16, 149-158. [CrossRef]

5. Vermeiren, L.; Devlieghere, F.; van Beest, M.; de Kruijf, N.; Debevere, J. Developments in the active packaging of foods. Trends Food Sci. Technol. 1999, 10, 77-86. [CrossRef]

6. Tian, F.; Decker, E.A.; Goddard, J.M. Controlling lipid oxidation of food by active packaging technologies. Food Funct. 2013, 4, 669. [CrossRef] [PubMed]

7. Cichello, S.A. Oxygen absorbers in food preservation: A review. J. Food Sci. Technol. 2014, 52, 1889-1895. [CrossRef] [PubMed]

8. Ahvenainen, R. New approaches in improving the shelf life of minimally processed fruit and vegetables. Trends Food Sci. Technol. 1996, 7, 179-187. [CrossRef]

9. Bessemans, N.; Verboven, P.; Verlinden, B.E.; Nicolaï, B.M. A novel type of dynamic controlled atmosphere storage based on the respiratory quotient (RQ-DCA). Postharvest Biol. Technol. 2016, 115, 91-102. [CrossRef]

10. Gill, C.O. Extending the storage life of raw chilled meats. Meat Sci. 1996, 43, 99-109. [CrossRef]

11. Simone, A. Inside Aseptic, 2nd ed.; GEA Procomac SpA: Sala Baganza, Italy, 2013.

12. Miesbauer, O.; Kiese, S.; Carmi, Y.; Kücükpinar, E.; Noller, K. Development of novel opaque and transparent barrier films for VIP-encapsulation Part-II: Barrier film production for VIPs. In 11th International Vacuum Insulation Symposium; Empa: Dübendorf, Switzerland, 2013; pp. 19-20.

13. Vasko, K.; Noller, K.; Mikula, M.; Amberg-Schwab, S.; Weber, U. Multilayer coatings for flexible high-barrier materials. Open Phys. 2009, 7, 371-378.

14. Amberg-Schwab, S.; Weber, U.; Burger, A.; Nique, S.; Xalter, R. Development of passive and active barrier coatings on the basis of inorganic-organic polymers. Monatshefte fur Chemie 2006, 137, 657-666. [CrossRef]

15. García-Torres, R.; Ponagandla, N.R.; Rouseff, R.L.; Goodrich-Schneider, R.M.; Reyes-De-Corcuera, J.I. Effects of dissolved oxygen in fruit juices and methods of removal. Compr. Rev. Food Sci. Food Saf. 2009, 8, 409-423. [CrossRef] 
16. Berlinet, B.C.; Brat, P.; Ducruet, V. Quality of Orange Juice in Barrier Packaging Material. Packag. Technol. Sci. 2008, 21, 279-286. [CrossRef]

17. Van Dijck, S.; Dessaint, A.; Deckers, J. Heat Resistant and Biaxially Stretched Blow-Molded Plastic Container Having a Base Movable to Accomodate Internal Vacuum Forces and Issued from a Double-Blow Process. WIPO Patent 2015/177112, 29 November 2015.

18. Dessaint, A.; Windelinckx, S. Hot-Fillable Plastic Container Having Vertical Pillars and Concave Deformable Sidewall Panels. Eur. Patent 2,698,320, 19 February 2014.

19. Min, D.B.; Boff, J.M. Chemistry and Reaction of Singlet Oxygen in Foods. Compr. Rev. Food Sci. Food Saf. 2002, 1, 58-72. [CrossRef]

20. DeRosa, M.C.; Crutchley, R.J. Photosensitized singlet oxygen and its applications. Coord. Chem. Rev. 2002, 233-234, 351-371. [CrossRef]

21. Jorgensen, M.; Norrman, K.; Krebs, F.C. Stability/degradation of polymer solar cells. Sol. Energy Mater. Sol. Cells 2008, 92, 686-714. [CrossRef]

22. Park, S.J.; Gesquiere, A.J.; Yu, J.; Barbara, P.F. Charge Injection and Photooxidation of Single Conjugated Polymer Molecules. J. Am. Chem. Soc. 2004, 126, 4116-4117. [CrossRef] [PubMed]

23. Cheng, Y.-J.; Yang, S.-H.; Hsu, C.-S. Synthesis of Conjugated Polymers for Organic Solar Cell Applications. Chem. Rev. 2009, 109, 5868-5923. [CrossRef] [PubMed]

24. Goes, M.; Verhoeven, J.W.; Hofstraat, H.; Brunner, K. OLED and PLED devices employing electrogenerated, intramolecular charge-transfer fluorescence. ChemPhysChem 2003, 4, 349-358. [CrossRef] [PubMed]

25. Schweitzer, C.; Schmidt, R. Physical mechanisms of generation and deactivation of singlet oxygen. Chem. Rev. 2003, 103, 1685-1757. [CrossRef] [PubMed]

26. Choe, E.; Min, D.B. Chemistry and Reactions of Reactive Oxygen Species in Foods. Crit. Rev. Food Sci. Nutr. 2006, 46, 1-22. [CrossRef] [PubMed]

27. Recamales, Á.F.; Sayago, A.; González, M.L.; Hernanz, D. The effect of time and storage conditions on the phenolic composition and colour of white wine. Food Res. Int. 2006, 39, 220-229. [CrossRef]

28. Mestdagh, F.; De Meulenaer, B.; De Clippeleer, J.; Devlieghere, F.; Huyghebaert, A. Protective influence of several packaging materials on light oxidation of milk. J. Dairy Sci. 2005, 88, 499-510. [CrossRef]

29. Cladman, W.; Scheffer, S.; Goodrich, N.; Griffiths, M.W. Shelf-life of milk packaged in plastic containers with and without treatment to reduce light transmission. Int. Dairy J. 1998, 8, 629-636. [CrossRef]

30. Sheraz, M.A.; Kazi, S.H.; Ahmed, S.; Anwar, Z.; Ahmad, I. Photo, thermal and chemical degradation of riboflavin. Beilstein J. Org. Chem. 2014, 10, 1999-2012. [CrossRef] [PubMed]

31. Ochiai, E. Mechanism of Catalysis By Metal Complexes in Autoxidation of an Olefin. Tetrahedron 1964, 20, 1819-1829. [CrossRef]

32. Pignatello, J.J.; Oliveros, E.; MacKay, A. Advanced Oxidation Processes for Organic Contaminant Destruction Based on the Fenton Reaction and Related Chemistry. Crit. Rev. Environ. Sci. Technol. 2006, 36, 1-84. [CrossRef]

33. Fenton, H.J.H. LXXIII.-Oxidation of tartaric acid in presence of iron. J. Chem. Soc. Trans. 1894, 65, 899-910. [CrossRef]

34. Kehrer, J.P. The Haber-Weiss reaction and mechanisms of toxicity. Toxicology 2000, 149, 43-50. [CrossRef]

35. Bouwman, E.; van Gorkum, R. A study of new manganese complexes as potential driers for alkyd paints. J. Coat. Technol. Res. 2007, 4, 491-503. [CrossRef]

36. Babuponnusami, A.; Muthukumar, K. A review on Fenton and improvements to the Fenton process for wastewater treatment. J. Environ. Chem. Eng. 2014, 2, 557-572. [CrossRef]

37. Comninellis, C.; Kapalka, A.; Malato, S.; Parsons, S.A.; Poulios, I.; Mantzavinos, D. Advanced oxidation processes for water treatment: Advances and trends for R\&D. J. Chem. Technol. Biotechnol. 2008, 83, 769-776.

38. Kuchel, L.; Brody, A.L.; Wicker, L. Oxygen and its reactions in beer. Packag. Technol. Sci. 2006, 19, $25-32$. [CrossRef]

39. Thomsen, M.K.; Kristensen, D.; Skibsted, L.H. Electron spin resonance spectroscopy for determination of the oxidative stability of food lipids. J. Am. Oil Chem. Soc. 2000, 77, 725-730. [CrossRef]

40. Zufall, C.; Tyrell, T. The Influence of Heavy Metal Ions on Beer Flavour Stability. J. Inst. Brew. 2008, 114, 134-142. [CrossRef] 
41. Pérez-López, A.J.; Saura, D.; Lorente, J.; Carbonell-Barrachina, Á.A. Limonene, linalool, $\alpha$-terpineol, and terpinen-4-ol as quality control parameters in mandarin juice processing. Eur. Food Res. Technol. 2006, 222, 281-285. [CrossRef]

42. Lu, F.S.H.; Bruheim, I.; Jacobsen, C. Maillard reaction and lipid peroxidation contribute to non-enzymatic browning in krill-based products: A model study on proposed mechanisms. Eur. J. Lipid Sci. Technol. 2015, 117, 421-430. [CrossRef]

43. Sun, H.; Lu, L.; Ge, C.; Tang, Y. Effect of Packaging Films on the Quality of Canola Oil under Photooxidation Conditions. Math. Probl. Eng. 2015, 2015, 764516. [CrossRef]

44. Vanderhaegen, B.; Neven, H.; Verachtert, H.; Derdelinckx, G. The chemistry of beer aging-A critical review. Food Chem. 2006, 95, 357-381. [CrossRef]

45. Schmidbauer, S.; Hohenleutner, A.; König, B. Studies on the photodegradation of red, green and blue phosphorescent OLED emitters. Beilstein J. Org. Chem. 2013, 9, 2088-2096. [CrossRef] [PubMed]

46. Ziegenbalg, D.; Kreisel, G. OLEDs as prospective light sources for microstructured photoreactors. Photochem. Photobiol. Sci. 2014, 13, 1005-1015. [CrossRef] [PubMed]

47. Danilewicz, J.C. Interaction of sulfur dioxide, polyphenols, and oxygen in a wine-model system: Central role of iron and copper. Am. J. Enol. Vitic. 2007, 58, 53-60.

48. Gómez-Plaza, E.; Cano-López, M. A review on micro-oxygenation of red wines: Claims, benefits and the underlying chemistry. Food Chem. 2011, 125, 1131-1140. [CrossRef]

49. Oliveira, C.M.; Ferreira, A.C.S.; De Freitas, V.; Silva, A.M.S. Oxidation mechanisms occurring in wines. Food Res. Int. 2011, 44, 1115-1126. [CrossRef]

50. Waterhouse, A.L.; Laurie, V.F. Oxidation of Wine Phenolics: A Critical Evaluation and Hypotheses. Am. J. Enol. Vitic. 2006, 3, 306-313.

51. Thellen, C.; Schirmer, S.; Ratto, J.A.; Finnigan, B.; Schmidt, D. Co-extrusion of multilayer poly(m-xylylene adipimide) nanocomposite films for high oxygen barrier packaging applications. J. Membr. Sci. 2009, 340, 45-51. [CrossRef]

52. Van Bree, I.; De Meulenaer, B.; Samapundo, S.; Vermeulen, A.; Ragaert, P.; Maes, K.C.; De Baets, B.; Devlieghere, F. Predicting the headspace oxygen level due to oxygen permeation across multilayer polymer packaging materials: A practical software simulation tool. Innov. Food Sci. Emerg. Technol. 2010, 11, 511-519. [CrossRef]

53. Tashiro, H.; Nakaya, M.; Hotta, A. Enhancement of the gas barrier property of polymers by DLC coating with organosilane interlayer. Diam. Relat. Mater. 2013, 35, 7-13. [CrossRef]

54. Standard Test Method for Oxygen Gas Transmission Rate Through Plastic Film and Sheeting Using a Coulometric Sensor; ASTM D3985-05(2010)e1; ASTM International: West Conshohocken, PA, USA, 2010.

55. Dhar, P.; Bhardwaj, U.; Kumar, A.; Katiyar, V. Poly (3-hydroxybutyrate)/cellulose nanocrystal films for food packaging applications: Barrier and migration studies. Polym. Eng. Sci. 2015, 55, 2388-2395. [CrossRef]

56. Liu, R.Y.F.; Hu, Y.S.; Schiraldi, D.A.; Hiltner, A.; Baer, E. Crystallinity and oxygen transport properties of PET bottle walls. J. Appl. Polym. Sci. 2004, 94, 671-677. [CrossRef]

57. Auras, R.; Harte, B.; Selke, S. Effect of water on the oxygen barrier properties of poly(ethylene terephthalate) and polylactide films. J. Appl. Polym. Sci. 2004, 92, 1790-1803. [CrossRef]

58. Knudsen, R.; Black, J.D. Polyamide-Polydiene Blends with Improved Oxygen Reactivity. U.S. Patent 8,409,680, 2 April 2013.

59. Folkeson, E. Determining the Oxygen Transmission Rate of Carton Packages; Report; Lund University: Lund, Sweden, 2012.

60. Yoshikawa, Y.; Nawata, T.; Goto, M.; Fujii, Y. Oxygen Indicator. U.S. Patent 4,169,811, 2 October 1979.

61. Lee, S.K.; Sheridan, M.; Mills, A. Novel UV-activated colorimetric oxygen indicator. Chem. Mater. 2005, 17, 2744-2751. [CrossRef]

62. Quaranta, M.; Borisov, S.M.; Klimant, I. Indicators for optical oxygen sensors. Bioanal. Rev. 2012, 4, $115-157$. [CrossRef] [PubMed]

63. Blinka, T.A.; Bull, C.; Barmore, C.R.; Speer, D.V. Method of Detecting the Permeability of an Object to Oxygen. U.S. Patent 5,583,047, 10 December 1996.

64. Baldini, F.; Bacci, M.; Cosi, F.; Del Bianco, A. Absorption-based optical-fibre oxygen sensor. Sens. Actuators B Chem. 1992, 7, 752-757. [CrossRef] 
65. Mills, A. Oxygen indicators and intelligent inks for packaging food. Chem. Soc. Rev. 2005, 34, $1003-1011$. [CrossRef] [PubMed]

66. Veale, J.R. Apparatus and Method for Nondestructive Monitoring of Gases in Sealed Containers. U.S. Patent 6,639,678, 28 October 2003.

67. Cocola, L.; Allermann, H.; Fedel, M.; Sønderby, S.; Tondello, G.; Bardenstein, A.; Poletto, L. Validation of an in-line non-destructive headspace oxygen sensor. Food Packag. Shelf Life 2016, 9, 38-44. [CrossRef]

68. Lund, A.; Jacobsen, T.; Hansen, K.V.; Mogensen, M. Limitations of potentiometric oxygen sensors operating at low oxygen levels. Sens. Actuators B Chem. 2011, 160, 1159-1167. [CrossRef]

69. Ramamoorthy, R.; Dutta, P.K.; Akbar, S.A. Oxygen sensors: Materials, methods, designs. J. Mater. Sci. 2003, 38, 4271-4282. [CrossRef]

70. Garza, A.C.; Bavisotto, V.S. Apparatus for and Method of Determining Oxygen and Carbon Dioxide in Sealed Containers. U.S. Patent 3,849,070, 19 November 1974.

71. Standard Test Method for Oxygen Transmission Rate Through Dry Packages Using a Coulometric Sensor; ASTM F1307-02; ASTM International: West Conshohocken, PA, USA, 2002.

72. Pascall, M.A.; Fernandez, U.; Gavara, R.; Allafi, A. Mathematical modeling, non-destructive analysis and a gas chromatographic method for headspace oxygen measurement of modified atmosphere packaged soy bread. J. Food Eng. 2008, 86, 501-507. [CrossRef]

73. Larsen, H.; Kohler, A.; Magnus, E.M. Ambient oxygen ingress rate method-an alternative method to Ox-Tran for measuring oxygen transmission rate of whole packages. Packag. Technol. Sci. 2000, 13, 233-241. [CrossRef]

74. Ullsten, N.H.; Hedenqvist, M.S. A new test method based on head space analysis to determine permeability to oxygen and carbon dioxide of flexible packaging. Polym. Test. 2003, 22, 291-295. [CrossRef]

75. Shahriari, M.R. Method and Composition for a Platinum Embedded Sol Gel Optical Chemical Sensor with Improved Sensitivity and Chemical Stability. U.S. Patent 2008/0199360, 21 August 2008.

76. Klimant, I.; Krause, C. Oxygen Sensors Disposed on a Microtiter Plate. U.S. Patent 2004/0171094, 2 September 2004.

77. Hatchett, D.W.; Bennett, B.L.; Devinder, P.S.S. Device and Method for Non-Invasive Oxygen Sensing of Sealed Packages. U.S. Patent 2007/0243618, 18 October 2007.

78. Huber, C.; Nguyen, T.-A.; Krause, C.; Humele, H.; Stangelmayer, A. Oxygen Ingress Measurement into PET Bottles using Optical-Chemical Sensor Technology. Monatsschrift für Brauwissenschaft 2006, 59, 5-15.

79. Bacigalupi, C.; Lemaistre, M.H.; Boutroy, N.; Bunel, C.; Peyron, S.; Guillard, V.; Chalier, P. Changes in nutritional and sensory properties of orange juice packed in PET bottles: An experimental and modelling approach. Food Chem. 2013, 141, 3827-3836. [CrossRef] [PubMed]

80. Di Felice, R.; Cazzola, D.; Cobror, S.; Oriani, L. Oxygen permeation in PET bottles with passive and active walls. Packag. Technol. Sci. 2008, 21, 405-415. [CrossRef]

81. Suzuki, T.; Hirata, S.; Yazaki, J.; Miyazaki, S.; Nohara, S. Multi-Layer Blow Molded Container and Process for Preparation Thereof. U.S. Patent 4,079,850, 21 March 1978.

82. Degroote, L. Rigid Plastic Container Having Gas-Barrier Properties and High Transparency. Eur. Patent 1,504,999, 9 February 2005.

83. Collette, W.N.; Schmidt, S.L. Oxygen Scavenging Composition for Multilayer Preform and Container. WIPO Patent 96/18685, 20 June 1996.

84. Collette, W.N.; Schmidt, S.L.; Krishnakumar, S.M. Multilayer Preform and Container with Polyethylene Naphthalate (PEN), and Method of Forming Same. U.S. Patent 5,976,653, 2 November 1999.

85. Akkapeddi, M.K.; Socci, E.P.; Kraft, T.J.; Pratt, J.D. Delamination-Resistant, Barrier Polyamide Compositions for 3-layer PET Beverage Bottles. U.S. Patent 2005/0009976, 13 January 2005.

86. Lagarón, J.M.; Cabedo, L.; Cava, D.; Feijoo, J.L.; Gavara, R.; Gimenez, E. Improving packaged food quality and safety. Part 2: Nanocomposites. Food Addit. Contam. 2005, 22, 994-998. [CrossRef] [PubMed]

87. Fasihi, M.; Abolghasemi, M.R. Oxygen barrier and mechanical properties of masterbatch-based PA6/nanoclay composite films. J. Appl. Polym. Sci. 2012, 125, E2-E8. [CrossRef]

88. Hu, Y.S.; Prattipati, V.; Hiltner, A.; Baer, E.; Mehta, S. Improving transparency of stretched PET/MXD6 blends by modifying PET with isophthalate. Polymer 2005, 46, 5202-5210. [CrossRef]

89. Grunlan, J.C.; Grigorian, A.; Hamilton, C.B.; Mehrabi, A.R. Effect of clay concentration on the oxygen permeability and optical properties of a modified poly(vinyl alcohol). J. Appl. Polym. Sci. 2004, 93, 1102-1109. [CrossRef] 
90. Zhang, X. Processing-structure-properties relationship of multilayer films. 1. Structure characterization. Polymer 2001, 42, 8179-8195. [CrossRef]

91. Kim, Y.J.; Germonprez, R. Barrier Compositions and Film Made Therefrom Having Improved Optical and Barrier Properties. U.S. Patent 5,314,987, 24 May 1994.

92. Lewis, J. Material challenge for flexible organic devices. Mater. Today 2006, 9, 38-45. [CrossRef]

93. Lewis, J.S.; Weaver, M.S. Thin-Film Permeation-Barrier Technology for Flexible Organic Light-Emitting Devices. IEEE J. Sel. Top. Quantum Electron. 2004, 10, 45-57. [CrossRef]

94. Burrows, P.E.; Graff, G.L.; Gross, M.E.; Martin, P.M.; Shi, M.K.; Hall, M.; Mast, E.; Bonham, C.; Bennett, W.; Sullivan, M.B. Ultra barrier flexible substrates for flat panel displays. Displays 2001, 22, 65-69. [CrossRef]

95. Kushida, H.; Kosugi, A.; Nagayama, H. Saturated Polyester Bottle-Shaped Container with Hard Coating and Method of Fabricating the Same. U.S. Patent 4,569,869, 11 February 1986.

96. Walker, F.H.; Pepe, F.R.; Dickenson, J.B. Packaging Materials Having Barrier Coatings Based on Water Epoxy Resin Copolymers. U.S. Patent 6,777,088, 17 August 2004.

97. Lange, J.; Nicolas, B.; Galy, J.; Gerard, J.-F. Influence of structure and chemical composition on oxygen permeability of crosslinked epoxy-amine coatings. Polymer 2002, 43, 5985-5994. [CrossRef]

98. Leterrier, Y. Durability of nanosized oxygen-barrier coatings on polymers. Prog. Mater. Sci. 2003, 48, 1-55. [CrossRef]

99. Howells, D.G.; Henry, B.M.; Leterrier, Y.; Månson, J.A.E.; Madocks, J.; Assender, H.E. Mechanical properties of SiOx gas barrier coatings on polyester films. Surf. Coat. Technol. 2008, 202, 3529-3537. [CrossRef]

100. Shirakura, A.; Nakaya, M.; Koga, Y.; Kodama, H.; Hasebe, T.; Suzuki, T. Diamond-like carbon films for PET bottles and medical applications. Thin Solid Films 2006, 494, 84-91. [CrossRef]

101. Leterrier, Y.; Andersons, J.; Pitton, Y.; Månson, J.-A.E. Adhesion of silicon oxide layers on poly (ethylene terephthalate). II: Effect of coating thickness on adhesive and cohesive strengths. J. Polym. Sci. B Polym. Phys. 1997, 35, 1463-1472. [CrossRef]

102. Greener, J.; Ng, K.C.; Vaeth, K.M.; Smith, T.M. Moisture Permeability Through Multilayered Barrier Films as Applied to Flexible OLED Display. J. Appl. Polym. Sci. 2007, 106, 3534-3542. [CrossRef]

103. Yamamoto, S.; Kodama, H.; Hasebe, T.; Shirakura, A.; Suzuki, T. Oxygen transmission of transparent diamond-like carbon films. Diam. Relat. Mater. 2005, 14, 1112-1115. [CrossRef]

104. Inagaki, N.; Tasaka, S.; Nakajima, T. Preparation of oxygen gas barrier polypropylene films by deposition of SiOx films plasma-polymerized from mixture of tetramethoxysilane and oxygen. J. Appl. Polym. Sci. 2000, 78, 2389-2397. [CrossRef]

105. Singh, B.; Bouchet, J.; Rochat, G.; Leterrier, Y.; Manson, J.A.E.; Fayet, P. Ultra-thin hybrid organic/inorganic gas barrier coatings on polymers. Surf. Coat. Technol. 2007, 201, 7107-7114. [CrossRef]

106. Hu, Y.S.; Prattipati, V.; Mehta, S.; Schiraldi, D.A.; Hiltner, A.; Baer, E. Improving gas barrier of PET by blending with aromatic polyamides. Polymer 2005, 46, 2685-2698. [CrossRef]

107. Pal, R. Permeation models for mixed matrix membranes. J. Colloid Interface Sci. 2008, 317, 191-198. [CrossRef] [PubMed]

108. Singh, T.; Kang, D.; Nair, S. Rigorous calculations of permeation in mixed-matrix membranes: Evaluation of interfacial equilibrium effects and permeability-based models. J. Membr. Sci. 2013, 448, 160-169. [CrossRef]

109. Vinh-Thang, H.; Kaliaguine, S. Predictive Models for Mixed-Matrix Membrane Performance: A Review. Chem. Rev. 2013, 113, 4980-5028. [CrossRef] [PubMed]

110. Datta, A.K. Biological and Bioenvironmental Heat and Mass Transport, 7th ed.; CRS Press: Boca Raton, FL, USA, 2002; ISBN 0-8247-0775-3.

111. Krook, M.; Morgan, G.; Hedenqvist, M.S. Barrier and mechanical properties of injection molded montmorillonite/polyesteramide nanocomposites. Polym. Eng. Sci. 2005, 45, 135-141. [CrossRef]

112. Sanchez-Garcia, M.D.; Gimenez, E.; Lagaron, J.M. Morphology and barrier properties of nanobiocomposites of poly(3-hydroxybutyrate) and layered silicates. J. Appl. Polym. Sci. 2008, 108, 2787-2801. [CrossRef]

113. Nielsen, L.E. Models for the Permeability of Filled Polymer Systems. J. Macromol. Sci. A Chem. 1967, 1, 929-942. [CrossRef]

114. Gonzo, E.E.; Parentis, L.; Gottifredi, J.C. Estimating models for predicting effective permeability of mixed matrix membranes. 2006, 277, 46-54. [CrossRef]

115. Doudou, B.B. Relationship between Draw Ratio and Strain-Induced Crystallinity in Uniaxially Hot-Drawn PET MXD6 Films. J. Plast. Film Sheeting 2005, 21, 233-251. [CrossRef] 
116. Callander, D.D.; Ferrari, G.; Giovannini, A.; Scrivani, M.T.; Ferrero, S. Dispersions of High Carboxyl Polyamides into Polyesters. U.S. Patent 2014/0107300, 17 April 2014.

117. Miyabe, T.; Kato, T.; Mitadera, J. Polyester-Based Resin Composition, Method for Producing Same, and Molding Using Resin Composition. U.S. Patent 2015/0030793, 29 January 2015.

118. Liu, Z.; Mehta, S.; Huang, X.; Schiraldi, D.A. Method to Make Single-Layer PET Bottles with High Barrier and Improved Clarity. U.S. Patent 7,919,159, 5 April 2011.

119. Choi, W.J.; Kim, H.J.; Yoon, K.H.; Kwon, O.H.; Hwang, C.I. Preparation and barrier property of poly(ethylene terephthalate)/clay nanocomposite using clay-supported catalyst. J. Appl. Polym. Sci. 2006, 100, 4875-4879. [CrossRef]

120. Kim, H.M.; Lee, J.K.; Lee, H.S. Transparent and high gas barrier films based on poly(vinyl alcohol)/graphene oxide composites. Thin Solid Films 2011, 519, 7766-7771. [CrossRef]

121. Prud'homme, R.K.; O'Neil, C.D.; Ozbas, B.; Aksay, I.A.; Register, R.A.; Adamson, D.H. Functional Graphene-Polymer Nanocomposites for Gas Barrier Applications. U.S. Patent 2010/0096595, 22 April 2010.

122. Gilmer, J.W.; Barbee, R.B.; Matayabas, J.C.J.; Lan, T. Polymer/Clay Nanocomposite Having Improved Gas Barrier Comprising a Clay Material with a Mixture of Two or More Organic Cations and a Process for Preparing Same. U.S. Patent 6,486,253, 22 November 2002.

123. Knoll, R.; Mueller, C. Containers Having Improved Barrier and Mechanical Properties. U.S. Patent 6,841,211, 11 January 2005.

124. Tammaji, K.S.; Palaniandavar, S.G.K.; Mohan, T.P.; Ramamoorthy, M.; Dillyraj, B.; Raja, M.S. Polyester Gas Barrier Resin and a Process Thereof. U.S. Patent 2008/0319117, 25 December 2008.

125. Choudalakis, G.; Gotsis, A.D. Permeability of polymer/clay nanocomposites: A review. Eur. Polym. J. 2009, 45, 967-984. [CrossRef]

126. Papageorgiou, G.Z.; Karandrea, E.; Giliopoulos, D.; Papageorgiou, D.G.; Ladavos, A.; Katerinopoulou, A.; Achilias, D.S.; Triantafyllidis, K.S.; Bikiaris, D.N. Effect of clay structure and type of organomodifier on the thermal properties of poly(ethylene terephthalate) based nanocomposites. Thermochim. Acta 2014, 576, 84-96. [CrossRef]

127. Silvestre, C.; Duraccio, D.; Cimmino, S. Food packaging based on polymer nanomaterials. Prog. Polym. Sci. 2011, 36, 1766-1782. [CrossRef]

128. Lin, J.; Shenogin, S.; Nazarenko, S. Oxygen solubility and specific volume of rigid amorphous fraction in semicrystalline poly(ethylene terephthalate). Polymer 2002, 43, 4733-4743. [CrossRef]

129. Priolo, M.A.; Gamboa, D.; Holder, K.M.; Grunlan, J.C. Super Gas Barrier of Transparent Polymer-Clay Multilayer Ultrathin Films. Nano Lett. 2010, 10, 4970-4974. [CrossRef] [PubMed]

130. Ferrari, M.C.; Carranza, S.; Bonnecaze, R.T.; Tung, K.K.; Freeman, B.D.; Paul, D.R. Modeling of oxygen scavenging for improved barrier behavior: Blend films. J. Membr. Sci. 2009, 329, 183-192. [CrossRef]

131. Di Maio, L.; Scarfato, P.; Galdi, M.R.; Incarnato, L. Development and oxygen scavenging performance of three-layer active PET films for food packaging. J. Appl. Polym. Sci. 2015, 132, 1-10. [CrossRef]

132. Simándi, L.I. Advances in Catalytic Activation of Dioxygen by Metal Complexes; Simandi, L.I., Ed.; Kluwer Academic Publishers: Dordrecht, The Netherlands, 2002; ISBN 0-306-47816-1.

133. Johnson, D.R.; Tian, F.; Roman, M.J.; Decker, E.A.; Goddard, J.M. Development of Iron-Chelating Poly(ethylene terephthalate) Packaging for Inhibiting Lipid Oxidation in Oil-in-Water Emulsions. J. Agric. Food Chem. 2015, 63, 5055-5060. [CrossRef] [PubMed]

134. López-Rubio, A.; Almenar, E.; Hernandez-Muñoz, P.; Lagarón, J.M.; Catalá, R.; Gavara, R. Overview of Active Polymer-Based Packaging Technologies for Food Applications. Food Rev. Int. 2004, 20, 357-387. [CrossRef]

135. Morita, Y.; Komatsu, T.; Inoue, Y. Oxygen Scavenger Container Used for Cap. U.S. Patent 4,756,436, 12 July 1988.

136. Yamada, S.; Sakuma, I.; Himeshima, Y.; Aoki, T.; Uemura, T.; Shirakura, A. Oxygen Scavenger. U.S. Patent 5,143,763, 1 September 1992.

137. Frisk, P. Oxygen Scavenging Container. U.S. Patent 5,804,236, 8 September 1998.

138. Baiano, A.; Marchitelli, V.; Tamagnone, P.; Del Nobile, M.A. Use of Active Packaging for Increasing Ascorbic Acid Retention in Food Beverages. J. Food Sci. 2006, 69, E502-E508. [CrossRef] 
139. Yuan, J.-P.; Chen, F. Degradation of Ascorbic Acid in Aqueous Solution. J. Agric. Food Chem. 1998, 46, 5078-5082. [CrossRef]

140. Van Bree, I.; Baetens, J.M.; Samapundo, S.; Devlieghere, F.; Laleman, R.; Vandekinderen, I.; Noseda, B.; Xhaferi, R.; De Baets, B.; De Meulenaer, B. Modelling the degradation kinetics of vitamin C in fruit juice in relation to the initial headspace oxygen concentration. Food Chem. 2012, 134, 207-214. [CrossRef]

141. Li, J.; Chotiko, A.; Narcisse, D.A.; Sathivel, S. Evaluation of alpha-tocopherol stability in soluble dietary fiber based nanofiber. LWT Food Sci. Technol. 2016, 68, 485-490. [CrossRef]

142. Bacigalupi, C.; Maurey, A.; Boutroy, N.; Peyron, S.; Avallone, S.; Chalier, P. Changes in nutritional value of a multi-vitamins fortified juice packed in glass and standard PET bottles. Food Control 2016, 60, 256-262. [CrossRef]

143. Maldonado, J.A.; Bruins, R.B.; Yang, T.; Wright, A.; Dunne, C.P.; Karwe, M.V. Browning and Ascorbic Acid Degradation in Meals Ready-to-Eat Pear Rations in Accelerated Shelf Life. J. Food Process. Preserv. 2015, 39, 2035-2042. [CrossRef]

144. Tikekar, R.V.; Anantheswaran, R.C.; Elias, R.J.; Laborde, L.F. Ultraviolet-induced oxidation of ascorbic acid in a model juice system: Identification of degradation products. J. Agric. Food Chem. 2011, 59, 8244-8248. [CrossRef] [PubMed]

145. Grudic, V.; Blagojevic, N.; Vukasinovic-Pesic, V.; Brasanac, S. Kinetics of degradation of ascorbic acid by cyclic voltammetry method. Chem. Ind. Chem. Eng. Q. 2015, 21, 351-357. [CrossRef]

146. Byun, Y.; Darby, D.; Cooksey, K.; Dawson, P.; Whiteside, S. Development of oxygen scavenging system containing a natural free radical scavenger and a transition metal. Food Chem. 2011, 124, 615-619. [CrossRef]

147. Teumac, F.N.; Zenner, B.D.; Ross, B.A.; Dearduff, L.A.; Rassouli, M.R. Metal Catalyzed Ascorbate Compounds as Oxygen Scavengers. U.S. Patent 6,465,065, 15 October 2002.

148. Koyama, M.; Oda, Y.; Yamada, M. Oxygen-Absorbing Resin Composition Containing Water-Absorbing Polymer, Olefin Resin and Oxygen Scavenger. U.S. Patent 5,274,024, 28 December 1993.

149. Tung, D.; Sisson, E.A.; Leckonby, R.A. Oxygen-Scavenging Resin Compositions Having Low Haze. U.S. Patent 6,780,916, 24 August 2004.

150. Busolo, M.A.; Lagaron, J.M. Oxygen scavenging polyolefin nanocomposite films containing an iron modified kaolinite of interest in active food packaging applications. Innov. Food Sci. Emerg. Technol. 2012, 16, 211-217. [CrossRef]

151. Mu, H.; Gao, H.; Chen, H.; Tao, F.; Fang, X.; Ge, L. A nanosised oxygen scavenger: Preparation and antioxidant application to roasted sunflower seeds and walnuts. Food Chem. 2013, 136, 245-250. [CrossRef] [PubMed]

152. Foltynowicz, B.Z.; Kozak, W.; Fiedorow, R. Studies of Oxygen Uptake on $\mathrm{O}_{2}$ Scavengers Prepared from Different Iron-containing Parent Substances. Packag. Technol. Sci. 2002, 15, 75-81. [CrossRef]

153. Al Ghatta, H. Oxygen-Scavenging Compositions and the Application Thereof in Packaging and Containers. U.S. Patent 2006/0208218, 21 September 2006.

154. Chau, C.-C.; Incorvia, S.A.; Powers, T.H.; Solovyov, S.E. Laminated and Thermoformed Articles Containing Oxygen Scavenger. U.S. Patent 2010/0282633, 11 November 2010.

155. Venkateshwaran, L.N.; Chokchi, D.J.; Chiang, W.L.; Tsai, B.C. Oxygen-Scavenging Compositions and Articles. U.S. Patent 5,744,056, 28 April 1998.

156. Carmichael, A.; Overend, A.S.; Rule, M.; Valus, R.J.; Leeming, C. Composition for Scavenging Oxygen, Container, Package and Closure Containing Said Composition. WIPO Patent 2010/116192, 14 October 2010.

157. Krikor, H.; Dessaint, A.; Verheyen, L. Seal Capable of Generating Molecular Hydrogen and Suitable for Closing a Container and for Scavenging Oxygen. Eur. Patent 2,404,753, 11 January 2012.

158. Hermans, A. Packaging Method and Packaging Comprising a Closed Oxygen-Scavenging Container Containing an Oxygen-Sensitive Substance. Eur. Patent 2,604,128, 19 June 2014.

159. Umegaki, T.; Yan, J.M.; Zhang, X.B.; Shioyama, H.; Kuriyama, N.; Xu, Q. Boron- and nitrogen-based chemical hydrogen storage materials. Int. J. Hydrogen Energy 2009, 34, 2303-2311. [CrossRef]

160. Liu, B.H.; Li, Z.P. A review: Hydrogen generation from borohydride hydrolysis reaction. J. Power Sources 2009, 187, 527-534. [CrossRef]

161. Sha, Y. The Mechanisms of the Fuel Cell Oxygen Reduction Reaction on Pt and Other 8-11 Column Metal Surfaces. Ph.D. Thesis, California Institute of Technology, Pasadena, CA, USA, 2011. 
162. Jiang, S.P. Hydrogen Oxidation at the Nickel and Platinum Electrodes on Yttria-Tetragonal Zirconia Electrolyte. J. Electrochem. Soc. 1997, 144, 3777. [CrossRef]

163. Wang, B. Recent development of non-platinum catalysts for oxygen reduction reaction. J. Power Sources 2005, 152, 1-15. [CrossRef]

164. Mori, K.; Hara, T.; Mizugaki, T.; Ebitani, K.; Kaneda, K. Hydroxyapatite-Supported Palladium Nanoclusters: A Highly Active Heterogeneous Catalyst for Selective Oxidation of Alcohols by Use of Molecular Oxygen. J. Am. Chem. Soc. 2004, 126, 10657-10666. [CrossRef] [PubMed]

165. Akkapeddi, M.K. In-Situ Polymerized Polymer-Platinum Group Metal Nanoparticle Blends and Oxygen Scavenging Containers Made Therefrom. U.S. Patent 2014/0034641, 6 February 2014.

166. Adzic, R.R.; Zhang, J.; Sasaki, K.; Vukmirovic, M.B.; Shao, M.; Wang, J.X.; Nilekar, A.U.; Mavrikakis, M.; Valerio, J.A.; Uribe, F. Platinum monolayer fuel cell electrocatalysts. Top. Catal. 2007, 46, 249-262. [CrossRef]

167. Markovic, N.M.; Ross, P.N., Jr. Surface science studies of model fuel cell electrocatalysts. Surf. Sci. Rep. 2002, 45, 117-229. [CrossRef]

168. Hicks, R.F.; Qi, H.; Young, M.L.; Lee, R.G. Structure sensitivity of methane oxidation over platinum and palladium. J. Catal. 1990, 122, 280-294. [CrossRef]

169. Rule, M.; Valus, R.J.; Tattum, S.B. Scavenging Oxygen. U.S. Patent 2010/0028499, 4 February 2010.

170. Cochran, M.A.; Folland, R.; Nicholas, J.W.; Robinson, M.E.R. Packaging. U.S. Patent 5,021,515, 4 June 1991.

171. Ball, M.J. Oxidation Studies of a Novel Barrier Polymer System. Ph.D. Thesis, Aston University, Birmingham, UK, 1995.

172. Patel, S.N. Thermal and Oxidative Degradation of an Aromatic Polyamide. Ph.D. Thesis, The University of Leeds, Leeds, UK, 1992.

173. Bokare, A.D.; Choi, W. Review of iron-free Fenton-like systems for activating $\mathrm{H}_{2} \mathrm{O}_{2}$ in advanced oxidation processes. J. Hazard. Mater. 2014, 275, 121-135. [CrossRef] [PubMed]

174. Menozzi, E.; Galfré, E.; Ruggeri, N. Use of Metal Complexes as Oxygen Absorber/Scavenger Elements for Packaging Applications. U.S. Patent 2012/0263974, 18 October 2012.

175. Schmidt, S.L.; Collette, W.N.; Coleman, E.A.; Krishnakumar, S.M. Transparent Package with Aliphatic Polyketone Oxygen Scavenger. U.S. Patent 5,952,066, 14 September 1999.

176. Cyr, M.J.; Clauberg, H.; Stewart, M.E.; Falling, S.N.; Rogers, M.E. Polyether Containing Polymers for Oxygen Scavenging. U.S. Patent 6,455,620, 24 September 2002.

177. Bandi, S.; Mehta, S.; Schiraldi, D.A. The mechanism of color generation in poly(ethylene terephthalate)/polyamide blends. Polym. Degrad. Stab. 2005, 88, 341-348. [CrossRef]

178. DeRoover, B.; Coppens, G.; Devaux, J.; Legras, R.; Momtaz, A. Contribution to poly(m-xylylene adipamide) characterization: Hydrolysis, condensation, and oxidation in the melt. J. Polym. Sci. A Polym. Chem. 1996, 34, 1039-1047. [CrossRef]

179. Drbohlav, J.I.; Yuan, Z. Oxygen Scavenging Resin with Short Induction Period. U.S. Patent 8,647,728, 11 February 2014.

180. Fava, F. Oxygen Scavenging Plastic Material. U.S. Patent 2013/0089686, 11 April 2013.

181. Cai, G.; Ching, Y.; Yang, H. Oxygen Scavenging Compositions Suitable for Heat Triggering. U.S. Patent 6,610,215, 26 August 2003.

182. Ve Speer, D.; Blinka, T.A.; Becraft, M.L. Methods and Compositions for Improved Initiation of Oxygen Scavenging. U.S. Patent 5,811,027, 22 September 1998.

183. Speer, D.V.; Roberts, W.P.; Morgan, C.R. Methods and Compositions for Oxygen Scavenging. U.S. Patent 5,211,875, 27 June 1993.

184. Behrendt, K.; Dauzvardis, M.J.; Hoch, R. Oxygen Scavenging Compositions, Articles Containing Same, and Methods of Their Use. U.S. Patent 2013/0285277, 31 October 2013.

185. Li, S.; Dauzvardis, M.J. Oxygen Scavengers, Compositions Comprising the Scavengers, and Articles Made from the Compositions. U.S. Patent 2016/0108207, 21 April 2016.

186. Deshpande, G.N. Thermoplastic Polymers Comprising Oxygen Scavenging Molecules. U.S. Patent 2014/0228524, 14 August 2014.

187. Share, P.; Evans, R.H. Oxygen-Scavenging Composition and Articles Thereof. U.S. Patent 2014/0262917, 18 September 2014.

188. Knudsen, R.; Murray, A. Polar Soluble Scavenging Compositions. U.S. Patent 2014/0145109, 29 May 2014. 
189. Stewart, M.E.; Armentrout, R.S. Oxygen-Scavenging Polymer Blends Suitable for Use in Packaging. U.S. Patent 7,985,456, 26 July 2011.

190. Richaud, E.; Okamba Diogo, O.; Fayolle, B.; Verdu, J.; Guilment, J.; Fernagut, F. Review: Auto-oxidation of aliphatic polyamides. Polym. Degrad. Stab. 2013, 98, 1929-1939. [CrossRef]

191. Coquillat, M.; Verdu, J.; Colin, X.; Audouin, L.; Nevière, R. Thermal oxidation of polybutadiene. Part 2: Mechanistic and kinetic schemes for additive-free non-crosslinked polybutadiene. Polym. Degrad. Stab. 2007, 92, 1334-1342. [CrossRef]

192. Li, H. Kinetics and Mechanisms of the Oxidation Processes for Unsaturated-Hydrocarbon-Modified Scavengers. Ph.D. Thesis, The University of Toledo, Toledo, Spain, 2010.

193. Rabek, J.F.; Lucki, J.; Ranby, B. Comparative studies of reactions of commercial polymers with molecular oxygen, singlet oxygen, atomic oxygen and ozone-I. Reactions with cis-1,4-polybutadiene. Eur. Polym. J. 1979, 15, 1089-1100. [CrossRef]

194. De Paoli, M.A. The chemical effects of photo-oxidation on butadiene rubber. Eur. Polym. J. 1983, 19, 761-768. [CrossRef]

195. Gijsman, P. Review on the thermo-oxidative degradation of polymers during processing and in service. E-Polymers 2008, 8, 1-34. [CrossRef]

196. Cahill, P.J.; Chen, S.Y. Oxygen Scavenging Condensation Copolymers for Bottles and Packaging Articles. U.S. Patent 6,083,585, 4 July 2000.

197. Hu, L.; Avakian, R.W. Oxygen Scavenging Terpolymers. Eur. Patent 2,443,169, 25 June 2015.

198. Liu, Z. Oxygen Scavenging Compositions and Method of Preparation. U.S. Patent 2008/0171169, 17 July 2008.

199. Ebner, C.L.; Berrier, A.L. Oxygen Scavenger Block Copolymers and Compositions. U.S. Patent 7,754,798, 13 July 2010.

(C) 2017 by the authors. Licensee MDPI, Basel, Switzerland. This article is an open access article distributed under the terms and conditions of the Creative Commons Attribution (CC BY) license (http:/ / creativecommons.org/licenses/by/4.0/). 